\title{
Avaliação do clima de ondas da praia de Ponta Negra (RN, Brasil) através do uso do SMC-Brasil e sua contribuição à gestão costeira*
}

\author{
Laura Ribas de Almeida ${ }^{\circledR}$, a ; Venerando Eustáquio Amaro; \\ Ana Maria Teixeira Marcelino ${ }^{\mathrm{a}}$; Ada Cristina Scudelari ${ }^{\mathrm{c}}$
}

\section{Resumo}

Para o planejamento e gestão efetivos da orla marítima, visando a implantação de obras de engenharia para contenção da erosão e a manutenção da linha de praia, é imprescindível o conhecimento dos forçantes hidrodinâmicos atuantes, destacandose o clima de ondas. No Brasil há uma carência de dados de ondas, que pode ser suprida através de bancos de dados gerados através de modelos numéricos (dados de reanálise e com downscaling), tal como o proposto pela Universidade de Cantábria/Espanha, cuja base de dados de ondas foi disponibilizada para o Brasil através do SMC-Brasil, que visa a transferência dessa base de dados, além de ferramentas e metodologia para uma melhor gestão do litoral brasileiro. Este trabalho utilizou o SMC-Brasil para analisar o clima de ondas da região costeira da praia de Ponta Negra localizada em Natal/RN, Nordeste do Brasil, que possui elevada importância turística, com amplo crescimento e ocupação urbana nas últimas décadas. O ponto selecionado como representativo do regime de ondas incidentes, localizado a uma cota batimétrica de $20 \mathrm{~m}$, na latitude $5,8775^{\circ} \mathrm{S} /$ longitude $35,0301^{\circ} \mathrm{W}$, apresenta as seguintes características de clima de ondas: predominância de ondas de leste-sudeste (ESE) em mais de $75 \%$ dos estados de mar, seguido de ondas de leste (E=20\%), sudeste (SE=3\%) e lestenordeste $(\mathrm{ENE}=2 \%)$. Sazonalmente, a predominância de ondulações provenientes de ESE ocorre em todas as estações do ano, porém no verão (Dezembro a Fevereiro) nota-se o aumento na participação de ondas provenientes de E. A altura de onda significativa (Hs) varia entre $0,5 \mathrm{~m}$ e $2,8 \mathrm{~m}$, com $75 \%$ dos estados de mar apresentando ondas inferiores a $1,6 \mathrm{~m}$. Ondas com Hs superior a 2,6m apresentam um período de retorno probabilístico de aproximadamente 10 anos. Em relação aos períodos de pico (Tp), os valores variam entre $4 \mathrm{~s}$ e $20 \mathrm{~s}$, sendo que $75 \%$ dos estados de mar apresentam Tp inferior a $8 \mathrm{~s}$. Ondas com Tp superior a 18s apresentam um período de retorno probabilístico de mais de 10 anos. A análise da distribuição conjunta de HsTp e Hs-Dir mostra que no ponto selecionado as ondas mais frequentes são as com Hs entre 1,3 e 1,7m, Tp em torno de $8 \mathrm{~s}$, provenientes da direção em torno de $110^{\circ}$. Na propagação dos casos espectrais verificou-se que a região sul da praia de Ponta Negra (área do Morro do Careca) é protegida da ondulação, alcançada por valores máximos de Hs de cerca de $1,5 \mathrm{~m}$ em eventos de tempestade. Isso ocorre tanto devido aos efeitos de difração e refração, mais evidentes nas ondulações de ESE e SE, quanto também aos efeitos de perda de energia devido ao fundo marinho deste setor, que apresenta uma batimetria mais suave, sendo mais dissipativa. Deste modo, destaca-se o aumento à exposição das ondas de sul para norte na praia de Ponta Negra, em direção à Via Costeira, com ondas de até 2,5m alcançando a linha de costa em eventos de tempestade. Os resultados deste estudo têm implicações relevantes para a gestão da zona costeira, como subsídio à melhoria do planejamento e gestão da orla, nas tomadas de decisões sobre o uso e ocupação dos terrenos próximos à linha de costa. Sugere-se que modelos similares sejam aplicados em outros locais como base para as ações de intervenção humana, em concordância com os princípios de gestão integrada e sustentável da zona costeira.

Palavras chave: base de dados de ondas, zona costeira, Sistema de Modelagem Costeira do Brasil.

\footnotetext{
(a) Corresponding author to whom correspondence should be addressed: <lauraribas.a@gmail.com>

a Instituto de Desenvolvimento Sustentável e Meio Ambiente (IDEMA), Av. Nascimento de Castro n 2127, CEP 59056-450, Natal, RN, Brasil.

b Universidade Federal do Rio Grande do Norte, Departamento de Geologia. Campus Universitário CEP 59078-970, Natal, RN, Brasil.

${ }^{c}$ Universidade Federal do Rio Grande do Norte, Departamento de Engenharia Civil. Campus Universitário CEP 59078-970, Natal, RN, Brasil.
}

* Submission: 28 JUN 2014; Peer review: 11 AUG 2014; Revised: 8 OCT 2014; Accepted: 18 NOV 2014; Available on-line: 20 NOV 2014
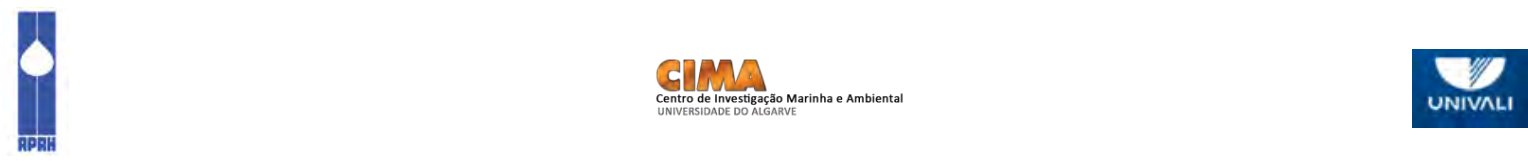


\begin{abstract}
Wave Climate Assessment on the Ponta Negra Beach (RN, Brazil) using SMC-Brasil and its contribution to coastal management
\end{abstract}

For effective planning and management of the coastline, from the implementation of engineering projects to contain erosion to the maintenance of the coastline, it is imperative to understand the hydrodynamic forces that influence coastal morphodynamics, especially wave climate. In Brazil instrumental data collection of waves on a large scale, systematically and in long and continuous time series is still challenging. Aiming fill this gap, some countries have developed methodologies which use numeric models, involve the reanalysis of previous data and perform downscaling in order to generate wave databases. One of these databases was proposed by the University of Cantabria, Spain and was used by SMC-Brasil, which aims to use the database, tools and methodology to improve the management of the Brazilian coast. This study used this database to analyze wave climate of coastal region of Ponta Negra beach located in Natal, northeast Brazil. Ponta Negra beach is important because of its fame for tourism and because it is a driving force behind the urban growth in this area. The wave climate was analyzed here as a basis of the beach erosion dynamics study in the region, as well as to develop a contribution to the management of public policy regarding seafront construction. Ponta Negra beach is a headland-bay beach located in the eastern sector of Rio Grande do Norte state. It is comprised of two sections: Ponta Negra beach itself and the beach along the Via Costeira, which extends to the North. The assessment of the role of wave climate at a point located at $20 \mathrm{~m}$ depth in the continental shelf (latitude $5.8775^{\circ} \mathrm{S} /$ longitude $35.0301^{\circ} \mathrm{W}$ ) by evaluating the SMC-Brasil wave database. The wave climate near the beach was determinate by the propagation of spectral wave cases associated with storms and normal conditions, at high and low tide. This representative point exhibited the following wave climate characteristics: predominance of waves from East-Southeast (ESE) and it represented more than 75\% of the wave direction, followed by waves from the East $(E=20 \%)$, Southeast $(S E=3 \%)$ and East-Northeast $(E N E=2 \%)$. The seasonal variation in wave direction is slight and the predominant direction is ESE in all seasons; however, in summer (the months of December, January and February), an increase in waves from the East can be observed. The significant wave height $\left(H_{s}\right)$ is between $0.5 \mathrm{~m}$ and $2.8 \mathrm{~m}$ and the waves are below $1.6 \mathrm{~m}$ in $75 \%$ of sea states. Waves with an $\mathrm{Hs}$ higher than $2.6 \mathrm{~m}$ showed a probabilistic return period of approximately 10 years. For peak periods (Tp), the values range from $4 \mathrm{~s}$ to $20 \mathrm{~s}$ and the Tp is below $8 \mathrm{~s}$ in $75 \%$ of sea states. Waves with a Tp higher than 18 s showed a probabilistic return period of more than 10 years. The analysis of the joint distribution of Hs to Tp and Hs to Direction shows that at this point, the most frequent waves are those with an Hs between 1.3 and $1.7 \mathrm{~m}$, a Tp around $8 \mathrm{~s}$ and from an $110^{\circ}$ direction. Based on the results obtained from the propagation of spectral wave cases during storms and under normal conditions, it can be seen that one of the characteristics of Ponta Negra beach is a wave height gradient with lower values in the southern region and increasing values along the Via Costeira. This is due to the effects of diffraction and refraction seen mainly in the SE and ESE waves and to the effects of energy loss because of the bathymetry in the southern region of Ponta Negra beach is typically gentler than the bathymetry in the North, with dissipative characteristics. In the protected area near Morro do Careca the maximum Hs values were registered at $1.5 \mathrm{~m}$ while in the northern region towards the Via Costeira waves up to $2.5 \mathrm{~m}$ were seen to reach the coastline during storms. By comparing the results from high and low tide wave propagations, it was found that in low tide the waves with the highest significant wave height reached the coastline. Visual assessments of the beach also showed that under these conditions and due to the erosion processes taking place at the coastline and the loss of sediment at the backshore of various sections of Ponta Negra beach, the waves reach the urban structures on the shoreline and are leading to its deterioration. And so, it can be concluded that based on the knowledge of the wave climate in a region such as Ponta Negra beach and based on the database from SMC-Brasil it is possible to plan, manage and take action to protect the coastal area more effectively and sustainably. Currently, the majority of the projects undertaken in the coastal zone do not take studies of marine dynamics into consideration and thus they are inefficient and have caused huge social, environmental and economic long-term damage. Through the use of the tools provided by SMC-Brasil, it has been shown that it is possible to obtain data and put it to use in the planning and management of the coastline. Thus, the results of this study have major implications for coastal zone management, as contribution to improve planning and management of seafront infrastructure, in decisions about the use and occupation of land near the coastline. It is suggested that similar models are implemented in other locations as the basis for the actions of human intervention, in accordance with the principles of integrated and sustainable management of the coastal zone.

Keywords: wave database, coastal zone, Coastal Modeling System of Brazil.

\section{Introdução}

As ondas, juntamente com marés e ventos, tornam a zona costeira um setor altamente dinâmico, intervindo de maneira significativa na mobilização, circulação e transporte de sedimentos, definindo as características morfológicas das praias. As condições da agitação marítima são influenciadas por fatores climáticos com variabilidades em diferentes escalas temporais, por processos não-lineares que controlam os estados de mar no decorrer de décadas, estações do ano e pelas flutuações de curto prazo de condições de climas locais (Reguero et al., 2012).

Portanto, nos estudos sobre a dinâmica costeira são imprescindíveis os diagnósticos das condições da agitação marítima em séries sistemáticas e contínuas, sobretudo na caracterização do clima de ondas que alcança a linha de costa, que interagem com as feições naturais ou antrópicas instaladas nos diversos setores da 
faixa costeira. A relevância desses estudos em regiões específicas do litoral reside no estabelecimento de parâmetros físicos precisos, que são subsídios fundamentais aos estudos de engenharia costeira e oceânica (Liu \& Losada, 2002). Tais parâmetros são aplicados em projetos de mitigação de processos erosivos instalados em praias urbanas, na condução de operações seguras de navegação, em projetos portuários e de plataformas petrolíferas, entre outras obras de engenharia; além de apoio à gestão costeira uma vez que é comum a existência de conflitos entre os aspectos de conservação/preservação ambiental e os interesses dos investidores privados e do poder público local na apropriação da zona costeira, por meio da privatização da região adjacente à linha de costa e/ou da implantação de equipamentos urbanos públicos (Marcelino, 1999).

As informações sobre o clima de ondas têm sido obtidas através de instrumentos como boias e satélites altimétricos, porém as boias geram medidas espacialmente pontuais e temporalmente reduzidas ou com interrupções, enquanto os satélites apresentam séries de coleta de dados a partir do ano de 1992 e com resolução temporal irregular (Reguero et al., 2012). Junta-se a isso o fato de que se enfrenta no Brasil uma escassez de bases de dados coletados in situ, representativos e de alta qualidade, que permitam a caracterização confiável do clima de ondas nas diversas regiões do extenso litoral brasileiro. A carência de séries longas de dados de ondas, temporalmente contínuas e espacialmente abrangentes, foi demonstrada em estudo sobre as alterações na dinâmica costeira e a influência das mudanças climáticas na vulnerabilidade da costa, para elaboração de políticas de desenvolvimento econômico e sustentável para a região da América Latina e Caribe (CEPAL, 2011). Neste estudo foi necessário o desenvolvimento $\mathrm{e}$ uso de uma base de dados de reanálise de ondas, com 60 anos de duração, para poder avaliar a vulnerabilidade e os riscos costeiros da América Latina e Caribe em longo prazo, pois a inexistência de dados de ondas nestes locais, incluindo o Brasil, impedia este tipo de avaliação.

Em função desta deficiência, quanto aos dados de ondas, há um crescente interesse em modelos que possam gerar séries de longo prazo de parâmetros de clima de ondas espacialmente homogêneas, tal como a Base de Dados de Ondas de Reanálise, Wave Reanalyses Databases - WRD (Reguero et al., 2012). A WRD constitui uma solução para locais onde não existem dados de onda obtidos a partir de medições instrumentais (Weisse \& Von Storch, 2010). Diversos esforços foram realizados para gerar bases de dados de ondas consistentes (p. ex., Sterl et al., 1998; WasaGroup, 1998; Cox \& Swail, 2001; Graham \& Diaz, 2001; Uppala et al., 2005; Caires \& Sterl, 2005a e 2005b; Pilar et al., 2008; Dodet et al., 2010), porém as alterações nas fontes de dados ao longo do tempo, os avanços nas técnicas de análise de dados e a evolução dos modelos de ondas de vento conduziram a uma não homogeneidade entre os resultados de ondas dos diferentes modos de reanálises, citados acima. Devido a esta variação, tanto no intervalo de tempo como na qualidade dos dados numéricos disponíveis sobre o clima de ondas, Reguero et al. (2012) apresentaram um novo modelo de WRD, denominado de Global Ocean Waves (GOW), com conjunto de dados atualizados de cobertura global, em série temporal longa (desde 1948) e de alta resolução temporal (a cada hora), calibrados e validados com medições instrumentais de boias oceânicas e por satélites altimétricos. Esta base de dados é recomendada na avaliação de ondas em águas oceânicas, tal como, a exemplo, em estudo sobre a variação interanual de ondas extremas no Oceano Atlântico Nordeste (Izaguirre et al., 2012), na América Central e do Sul (Izaguirre et al., 2013).

Apesar das bases de dados do tipo WRD apresentarem diversas vantagens, tais como uma boa cobertura espacial e o fornecimento de séries temporais contínuas de parâmetros de ondas e dados climáticos em períodos de tempo significativamente longos (p.ex. por mais de 40 anos), especialmente relevantes para os locais sem dados medidos instrumentalmente, há restrições quanto ao seu uso. Na base de dados WRD, as ondas são pobremente representadas em áreas de águas rasas, porque a resolução espacial não é suficientemente detalhada $\mathrm{e}$ as transformações de onda, devido à interação com a morfologia do substrato marinho raso, normalmente não são modelados (Camus et al., 2013). Para a solução deste problema é necessário uma modelagem destes processos de transformação das ondas, com base no aumento da resolução espacial, processo este conhecido como downscaling (Camus et al., 2011b). Deste modo, os dados GOW foram submetidos a este procedimento, gerando a base de dados de ondas de reanálise para 40 anos (de 1948 a 2008) para águas intermediárias e rasas, denominada Downscaled Ocean Waves (DOW), com alta resolução espacial e devidamente validada (Camus et al., 2013).

Esta base de dados DOW foi testada por Guanche et al. (2013) e utilizada na avaliação de efeitos das mudanças climáticas globais nas zonas costeiras da América Latina e Caribe (CEPAL, 2011; Reguero et al., 2013). Recentemente, esta base de dados DOW foi disponibilizada através do Sistema de Modelagem Costeira do Brasil (SMC-Brasil), para todo o litoral brasileiro (SMC-Brasil, 2014a).

O SMC-Brasil foi desenvolvido pelo Instituto de Hidráulica Ambiental da Cantábria (IHCantabria / Universidad de Cantabria) e transferido ao Brasil através do estabelecimento de um projeto de colaboração internacional entre Brasil e Espanha, intitulado "Transferencia de metodologías y herramien 
tas de apoyo a la gestión del litoral brasileño" (Oliveira, 2013). O SMC-Brasil é uma ferramenta que inclui, além das bases de dados de dinâmica marinha, modelos numéricos similares à versão espanhola do sistema (González et al., 2007), como o Modelo de Morfodinâmica de Praias (MOPLA), que por sua vez consiste dos Modelos de Propagação de Onda (OLUCA) e Modelos de Correntes Geradas pela Arrebentação das Ondas em Praias (COPLA), assim como metodologias que permitem estudar os processos costeiros e quantificar as variações que sofre o litoral como consequência de eventos naturais ou de atuações humanas na costa. Estes modelos foram aplicados e calibrados em diversos estudos, podendo-se citar Liu \& Losada (2002), González et al. (2007), Medellín et al. (2008), Restrepo et al. (2009), Tintoré et al., (2009), Raabe et al. (2010), Martínez et al. (2011).

Um dos objetivos do projeto de colaboração internacional, citado anteriormente, é o de fortalecer os órgãos de gestão que lidam com planejamento e controle ambiental. Considerando que a orla marítima é o espaço para o qual convergem políticas públicas de natureza patrimonial e ambiental, no Brasil foi instituída a forma de gestão compartilhada desse espaço terrestre e marítimo com a implementação dos Planos de Gestão Integrada da Orla Marítima (conhecido como Projeto Orla), uma ação conjunta entre o Ministério do Meio Ambiente e o Ministério do Planejamento, Orçamento e Gestão, no âmbito da Secretaria do Patrimônio da União (SPU/MP).

O Projeto Orla busca o ordenamento dos espaços litorâneos sob o domínio da União, promovendo a aproximação das políticas ambiental e patrimonial, articuladas com as esferas de governo estadual, municipal e da sociedade. Conforme mencionam os textos do Ministério do Meio Ambiente que subsidiam essa ação pública (MMA, 2006), o objetivo primeiro do projeto é compatibilizar as políticas ambiental e patrimonial do Governo Federal no trato dos espaços litorâneos sob a propriedade ou guarda da União, inicialmente buscando uma nova abordagem ao uso e gestão dos terrenos de marinha, como forma de consolidar uma orientação cooperativa e harmônica entre as ações e políticas praticadas na orla marítima. Contudo, apesar de existirem iniciativas do poder público em dotar as administrações municipais de instrumentos de normatização do uso e ocupação do solo, tais normas não têm assegurado o enfrentamento adequado da tendência de ocupação desordenada da costa. A seleção de áreas costeiras para construção de empreendimentos tem demonstrado, na maior parte dos casos, a irracionalidade dos investimentos do capital privado e público. Geralmente são escolhidos locais de grande valor cênico, mas que geralmente são instáveis fisicamente e quase sempre protegidas por legislação ambiental. Ainda não se confi gurou entre os investidores a consciência de que a paisagem e os recursos ambientais são bens de valor coletivo, que representam a base indispensável ao investimento de capital e que a sua manutenção é a garantia para o investimento realizado (Marcelino, 1999).

Desta maneira, para fortalecer os órgãos de gestão que lidam com planejamento e controle ambiental da orla marítima e colaborar com subsídios aos gestores, visando um melhor ordenamento da orla marítima, o SMC-Brasil foi introduzido no país, sendo a princípio tratado como tema de algumas dissertações que tiveram o objetivo de testar a base de dados e os modelos de propagação de ondas, como estudos de caso nos Estados de Santa Catarina (Almeida, 2013) e São Paulo (Luca, 2011). Em um segundo momento sua aplicação pretendeu avaliar a funcionalidade operacional do SMC-Brasil junto a estes órgãos, com sua aplicação em estudos na praia de Ponta Negra em Natal / Rio Grande do Norte (RN) e na Praia de Pau Amarelo em Paulista / Pernambuco (PE). Tais estudos tiveram como objetivo exercitar o uso das ferramentas disponíveis no SMCBrasil, por meio do aporte de dados específicos da dinâmica marinha e da avaliação dos seus efeitos sobre a linha de costa em áreas urbanas. A ideia principal do uso desta ferramenta pelos órgãos ambientais é o de dar subsídios para o planejamento territorial da zona costeira, com ênfase na conservação tanto de áreas adensadas quanto àquelas com características de zonas rurais, mas que demonstrem tendências de expansão urbana e/ou de implantação de estruturas de produção econômica, em função de potencialidades para exploração de recursos naturais.

O presente trabalho apresenta parte dos resultados do estudo na praia de Ponta Negra em Natal (RN), sendo esta a primeira publicação do uso do SMC-Brasil na região. A praia de Ponta Negra, principal praia urbana da cidade de Natal, sofre há décadas com intensos processos erosivos que comprometem seu valor socioeconômico, largamente baseado no turismo que tem como atrativo principal a paisagem e o uso da praia para lazer. Esta praia detém um significado especial para a população de Natal, fazendo parte de sua identidade e do imaginário coletivo e se destaca no contexto social da cidade, por representar forte referência visual, a partir do monumento natural conhecido como Morro do Careca, hoje ameaçado por construções que contornam a enseada. Atualmente, a enseada em que está inserida a praia de Ponta Negra é caracterizada como área de empreendimentos hoteleiros e de apoio ao turismo de alta relevância socioeconômica ao $\mathrm{RN}$.

Nas últimas décadas, a praia de Ponta Negra foi objeto de acentuado processo de urbanização, representado pela ampliação do número de construções e consequente modificação da orla marítima sem que fossem considerados os aspectos da evolução costeira de dinâ 
mica natural. Essas ações promoveram a desfiguração dos setores de pós-praia e das dunas vegetadas, com a ocupação da orla sem o adequado reconhecimento das características geológico-geomorfológicas da região, sobretudo no quadro de interação com a dinâmica dos processos costeiros entre o sistema praia-duna (Amaro et al., 2014). A intervenção pública, com a urbanização da Praia de Ponta Negra, cujo projeto incluiu a construção de um passeio público, com quiosques e manutenção da circulação de veículos em suas adjacências, fez com que se instalasse um conflito entre a gestão ambiental e territorial exercida pela prefeitura do município e os interesses dos quiosqueiros e demais usuários da praia. A implantação dessa obra atendeu aos interesses de empreendedores da área do turismo e a população natalense, porém a fragilidade ambiental da orla marítima, susceptível a qualquer intervenção que ocupe a linha de costa, provavelmente acentuou o processo erosivo.

Tendo em vista a precariedade de dados medidos in situ e do interesse do poder público em atuar na praia de Ponta Negra, o objetivo deste estudo foi determinar o clima de ondas na região da praia de Ponta Negra, tanto na zona exterior (águas intermediárias) quanto próximo à linha de costa, utilizando os dados de ondas e modelos de propagação disponíveis no SMC-Brasil, colaborando desta maneira para o entendimento da dinâmica marinha da região. Este estudo também visou gerar subsídios ao planejamento e à gestão desse importante trecho da orla marítima de Natal, para que sejam apropriados pelos órgãos gestores das políticas de uso e ocupação da orla marítima como, por exemplo, o Comitê Gestor da Orla Marítima e a Prefeitura de Natal, além das demais instituições que desenvolvem atividades na região costeira, sobretudo nas revisões e ajustes ao Plano Diretor da cidade.

\section{Características da área de estudo}

\subsection{Localização}

A praia de Ponta Negra está localizada no setor oriental do litoral do estado do Rio Grande do Norte (RN), Nordeste do Brasil (lat. 5,52 ${ }^{\circ} \mathrm{S}$; long. $35,10^{\circ} \mathrm{W}$ ), e se configura como a principal praia urbana da cidade do Natal, com cerca de $4 \mathrm{~km}$ de extensão (Figura 1). Na extremidade sul da praia de Ponta Negra localiza-se a duna vegetada conhecida como Morro do Careca, importante ponto de interesse turístico.

\subsection{Aspectos Climáticos}

Segundo Barros et al. (2013), na região de Natal a temperatura diária média do ar é de $24,4^{\circ} \mathrm{C}$, variando entre $21,8^{\circ} \mathrm{C}$ e $30,2^{\circ} \mathrm{C}$, com ventos contínuos de baixa intensidade (média de $4,4 \mathrm{~m} / \mathrm{s}$ ) que sopram de sudeste em $86 \%$ dos casos, qualificados como ventos alísios de sudeste. A precipitação média anual é de $1.500 \mathrm{~mm}$ e apresenta grande oscilação temporal, variando mensalmente de $17,5 \mathrm{~mm}$ a $204,5 \mathrm{~mm}$, com alternância de chuvas intensas no verão-outono e períodos de estiagem no inverno-primavera. Sendo assim, o clima da região de Natal, segundo a classificação climática de Köppen, é do tipo As definido como clima tropical chuvoso quente (Vianello \& Alves, 1991).

Para o litoral do RN há dados sobre o nível do mar registrados para o Porto de Natal, onde se classifica o regime de maré como de mesomarés semidiurnas, com amplitudes médias de marés de sizígia em torno de $2,2 \mathrm{~m}$, enquanto que nas marés de quadratura a amplitude média de $1,1 \mathrm{~m}$ (Carta náutica DHN/MB, n. ${ }^{\circ} 810$ Proximidades do Porto de Natal; DHN, 2009). Estimativas das variações do nível médio do mar em 60 anos (1948 até 2008), provenientes da base de dados do SMC-Brasil, indicam que na região em frente à praia de Ponta Negra a maré astronômica apresenta muito mais importância na variação do nível médio do mar (amplitude máxima de 2,6 $\mathrm{m}$ ) do que a maré meteorológica (amplitude máxima de $0,2 \mathrm{~m}$ ).

\subsection{Aspectos Geológico-Geomorfológicos}

A praia de Ponta Negra localiza-se na faixa sedimentar denominada de Bacia Pernambuco-Paraíba, constituída por rochas sedimentares do Cretáceo, recobertas por rochas do Grupo Barreiras e sedimentos Quaternários, como dunas, rochas praiais (beachrocks), terraços marinhos, terraços aluvionares e coberturas arenosas diversas. As principais feições geomorfológicas encontradas são as praias arenosas planas e estreitas, ladeadas por falésias ativas, tabuleiros costeiros, campos de dunas, linhas de recifes de arenitos praiais (beachrocks) e planícies flúvio-estuarinas (Vital et al., 2006). Ainda quanto às características morfológicas, a praia de Ponta Negra está inserida em baía do tipo enseada, ou forma em zeta, composta por dois trechos: a praia de Ponta Negra em si e a praia da Via Costeira, que se prolonga para norte. Portanto, a forma de praia em enseada tem aproximadamente $10 \mathrm{~km}$ de extensão e vai desde o Morro do Careca, na porção sul da praia de Ponta Negra, até a Ponta de Mãe Luisa, extremidade norte da Via Costeira (Figura 2).

A plataforma continental no trecho em frente à Natal apresenta a quebra entre 50 e $100 \mathrm{~m}$ de profundidade, localizada a aproximadamente $25 \mathrm{~km}$ da costa. Os sedimentos que recobrem essa porção da plataforma continental do RN são de origem terrígena até cerca de $20 \mathrm{~m}$ e carbonáticos a partir de então, prosseguindo até o talude continental (Vital et al., 2005). O principal rio do litoral oriental do RN é o rio Potengi, que corta a cidade de Natal. Na zona costeira submersa e adjacente à área de estudo ocorrem algumas feições que podem influenciar na propagação das ondas e no sistema de correntes da região, como a irregularidade na quebra da 


\section{PRAIA DE PONTA NEGRA - Natal, RN, Brasil}

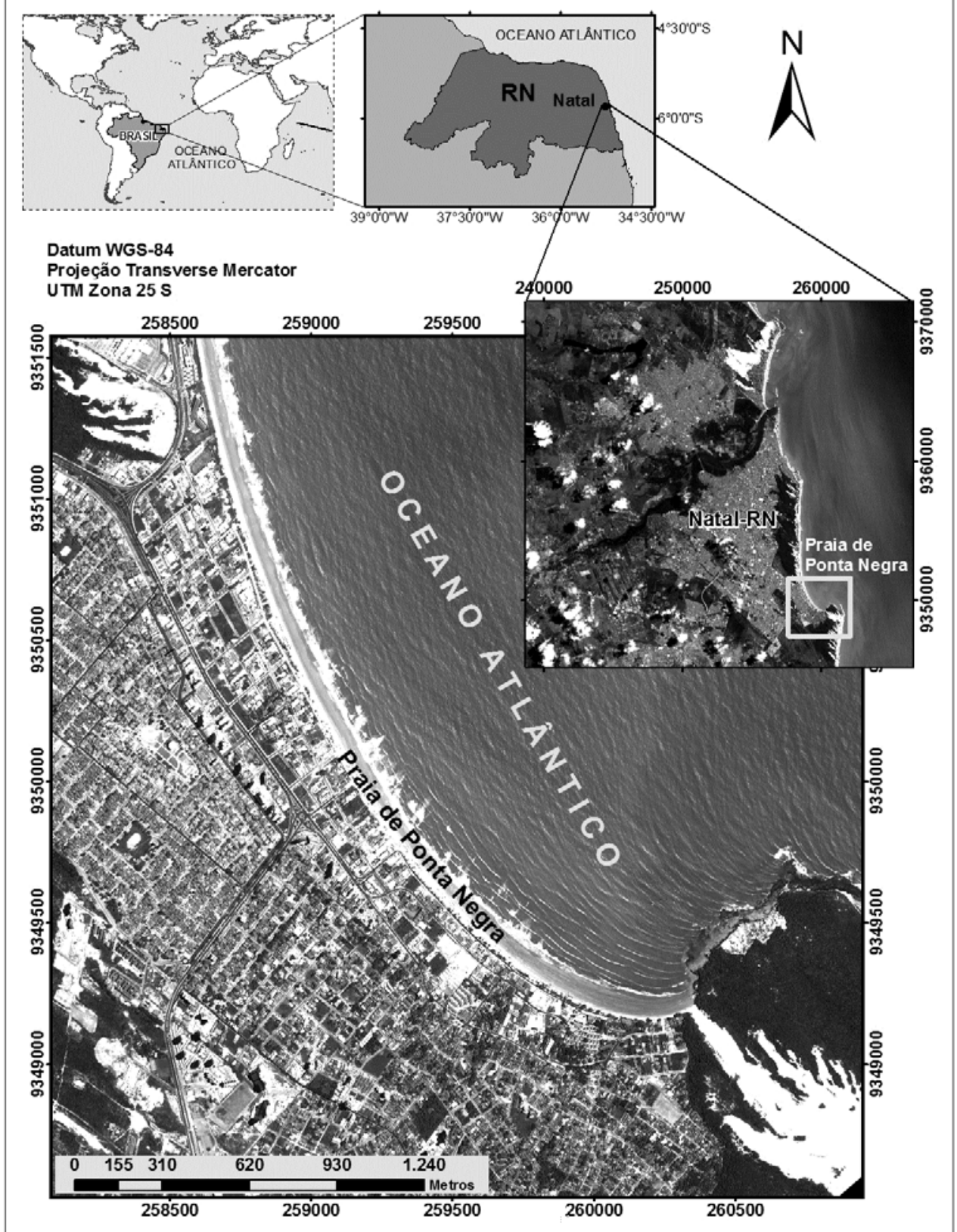

Figura 1 - Localização da área de estudo.

Figure 1 - Location of the study area.

plataforma provocada pelo canion submerso do rio Potengi e o promontório subjacente ao Morro do Careca (Figura 2).

\section{Materiais e métodos}

\subsection{Dados Batimétricos}

Neste estudo utilizou-se a batimetria regional proveniente da base de dados do SMC-Brasil, baseada na digitalização das cartas náuticas da Marinha do Brasil. A batimetria de detalhe utilizada para caracterizar a região da praia de Ponta Negra foi a realizada em Novembro de 2012 por Ferreira et al. (2014), que com preendeu o levantamento topobatimétrico da região do pós-praia até uma profundidade de $7-10 \mathrm{~m}$ na praia de Ponta Negra. Os Modelos Digitais de Elevação (MDE), integrados da topografia e da batimetria, foram gerados pela interpolação com uso da técnica Triangulated Irregular Network (TIN) e os pontos foram conectados de acordo com a triangulação de Delaunay, a qual usa o critério da maximização dos ângulos mínimos de cada triângulo (Santos et al., 2011, Amaro et al. 2013).

Para o setor da Via Costeira, que compreende a continuação da enseada da praia de Ponta Negra, a batimetria geral foi melhorada através da digitalização das isóbatas da Carta Náutica $n^{\circ} 810$ (DHN, 2009) apri 


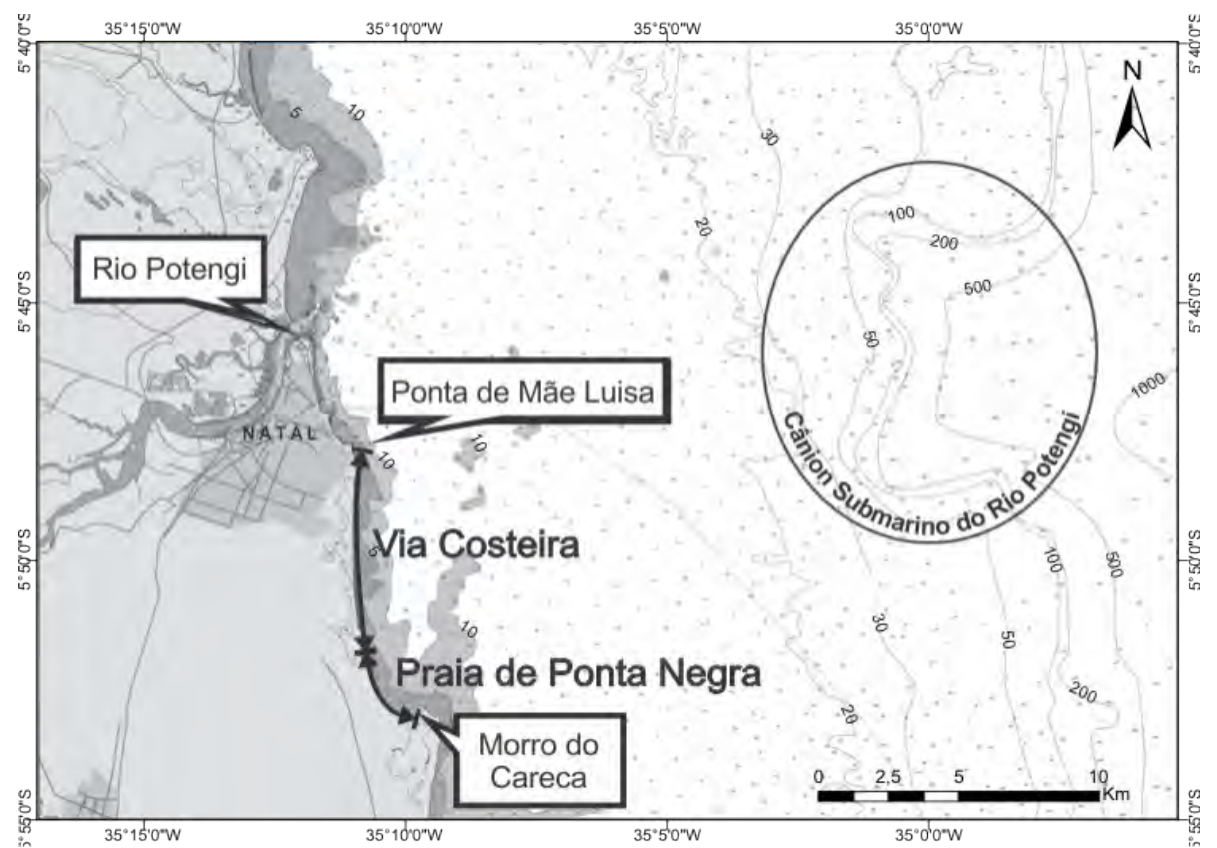

Figura 2 - Elementos morfológicos na zona costeira adjacente à área de estudo (mod. da Carta Náutica $\left.\mathrm{n}^{\circ} 810, \mathrm{DHN}, 2009\right)$.

Figure 2 - Morphological elements of the coastal area near the study area (mod. from the Nautical Chart $\left.n^{\circ} .810, D H N, 2009\right)$.

morada através da digitalização dos pontos e das isóbatas da Carta Náutica $n^{\circ} 800$ (DHN, 1972), adicionando desta maneira dados batimétricos à zona adjacente à área de estudo.

\subsection{Base de Dados de Ondas}

A base de dados de ondas incluída no SMC-Brasil foi gerada em duas etapas, conforme as metodologias apresentadas por Reguero et al. (2012), Camus et al. (2011b) e Camus et al. (2013). A primeira etapa consiste na geração de dados de ondas na região de águas profundas, através de uma reanálise global, com simulação numérica das condições de ondas durante um período longo sobre a superfície do oceano usando forçantes globais, ou seja, a variabilidade de ventos globais e cobertura de gelo que atuam na geração de ondas em escala global. As malhas usadas para região do Brasil tem resolução de $0,25^{\circ}$ e utilizaram como fonte batimétrica o General Bathymetric Chart of the Oceans (GEBCO). A simulação numérica realizou-se com o modelo Wave Watch III (WWIII), versão 2.2 (Tolman, 2002) e foi forçado com a reanálise atmosférica realiza da pelo National Center for Environmental Prediction (NCEP) e o National Center for Atmospheric Research (NCAR), que incluem a variabilidade de ventos globais

e de cobertura de gelo, sobre uma batimetria, com resolução espacial de $1,9^{\circ}$ e resolução temporal de 6 horas para o período de 1948 a 2009. O resultado obtido consiste num conjunto de séries de estados de mar em cada um dos nós das malhas, os pontos GOW. Tais dados foram calibrados utilizando medições de satélites com radares altimétricos (Tomás, 2008).

A segunda etapa trata da aproximação dos dados de ondas da região costeira, através de um downscaling dos pontos GOW. Além do resultado dos pontos GOW, contou-se com os campos de vento da reanálise global NCEP/NCAR a 10 metros de altura. A resolução espacial é de $1,9^{\circ} \times 1,9^{\circ}$ e temporal de 6 horas para o período de 1948-2009. No downscaling utilizaram-se malhas retangulares com resolução de aproximadamente $0,01^{\circ} \times 0,008^{\circ}$ (o que corresponde a cerca de $1,11 \mathrm{~km} \times$ $0,89 \mathrm{~km})$ e tendo as informações batimétricas aperfeiçoadas através da digitalização das cartas náuticas da Marinha do Brasil. Devido ao grande número de casos a serem propagados, recorreu-se a técnicas estatísticas que permitem reduzi-los a um número viável a serem propagados sem que haja perda da variabilidade que as séries representam, possível com o emprego do método de Análise das Componentes Principais e do algoritmo de Máxima Dissimilaridade (MaxDis) proposto por Camus et al. (2011a). Uma vez selecionados os casos representativos do universo global de casos a propagar, utilizando as técnicas estatísticas citadas, os mesmos foram propagados pelo modelo de terceira geração $\mathrm{Si}$ mulating Waves Nearshore (SWAN), desenvolvido pela Delft University of Technology (Booij et al., 1999), com posterior reconstrução da base de dados mediante a técnica de interpolação Radial Basis Functions (RBF) de Franke (1982). O resultado final é um conjunto de dados representativos de 60 anos de observações (de 1948 a 2008) em pontos denominados DOW disponibilizados 
em cada nó da malha, com parâmetros de altura de onda significativa $(\mathrm{Hs})$, período médio $(\mathrm{Tm})$, período de pico $(\mathrm{Tp})$ e direção média das ondas $(\theta \mathrm{m})$. Tais dados foram devidamente validados, sendo que a fonte dos dados in situ e metodologia estão descritas no Documento Temático de Ondas (SMC-Brasil, 2014b).

\subsection{Definição do Ponto da Base de Dados de Ondas}

$\mathrm{Na}$ caracterização do clima marítimo da região, diversos pontos DOW foram avaliados, tanto em águas profundas (profundidades superiores a $1000 \mathrm{~m}$ ) quanto em águas intermediárias (profundidades entre 13 e $20 \mathrm{~m}$ ). Em função das possíveis interferências que o talude continental pode ter sobre os espectros de ondas, principalmente aqueles com maiores comprimento de onda, o ideal seria a propagação dos casos desde antes da quebra da plataforma.

Assim, propagações foram efetuadas pelos autores deste artigo, através do modelo OLUCA-SP (descrito no próximo tópico), onde foram utilizados dados de ondas extremas, aquelas com probabilidade de retorno de 10 anos, que para a região apresentaram valores de $\mathrm{Hs}=3 \mathrm{~m}$ e $\mathrm{Tp}=14 \mathrm{~s}$. Estas propagações indicaram que, para estes casos, a feição morfológica conhecida como cânion do rio Potengi pode influenciar na propagação do clima de ondas, formando desde zonas de sombra até zonas de concentração de ondulação.

A propagação a partir destes pontos DOW até à linha de costa exige a utilização de malhas muito amplas. Porém, devido a limitações do modelo de propagação, principalmente quanto à necessidade de malhas de alta resolução que sejam capazes de modelar os efeitos locais em ondas de comprimento mediano, a aplicação do modelo desde águas profundas, para a região adjacente a Natal (RN), não é indicada. Isso porque o modelo é adequado para estudos com área limitada a efeitos locais. Deste modo, após análise dos resultados inicialmente obtidos e comparação com informações pretéritas de ondas (Hidroconsult, 1979; Tavares Junior, 1979), respeitando-se as limitações impostas pela modelagem, foi necessário que se determinasse o ponto inicial de propagação desde águas intermediárias até a zona de estudo.

Sendo assim, alguns pontos DOW, localizados em águas intermediárias (na cota batimétrica de $20 \mathrm{~m}$ ), foram avaliados para verificar a possível influência do cânion submerso do rio Potengi e a determinação do ponto DOW representativo do clima de ondas nesta cota batimétrica. A localização dos pontos DOW avaliados, em relação ao posicionamento do cânion submarino, pode ser observada na figura 3 . Na figura 4 estão apresentados, de maneira comparativa, os diferentes valores dos parâmetros de onda espectral dos pontos avaliados, onde pode-se observar que as diferenças de
$\mathrm{Tp} 50 \%$ e Tp12 são as mais significativas, principalmente para ondulações provenientes de ENE e E. Nesta figura, em uma análise visual, observa-se que o ponto $\mathrm{P} 2$ apresenta maior variação de dados em relação aos outros dois pontos avaliados sendo, aparentemente, o mais afetado pela presença do cânion submerso, pois se localiza justamente em frente e sofre assim efeitos de sombreamento.

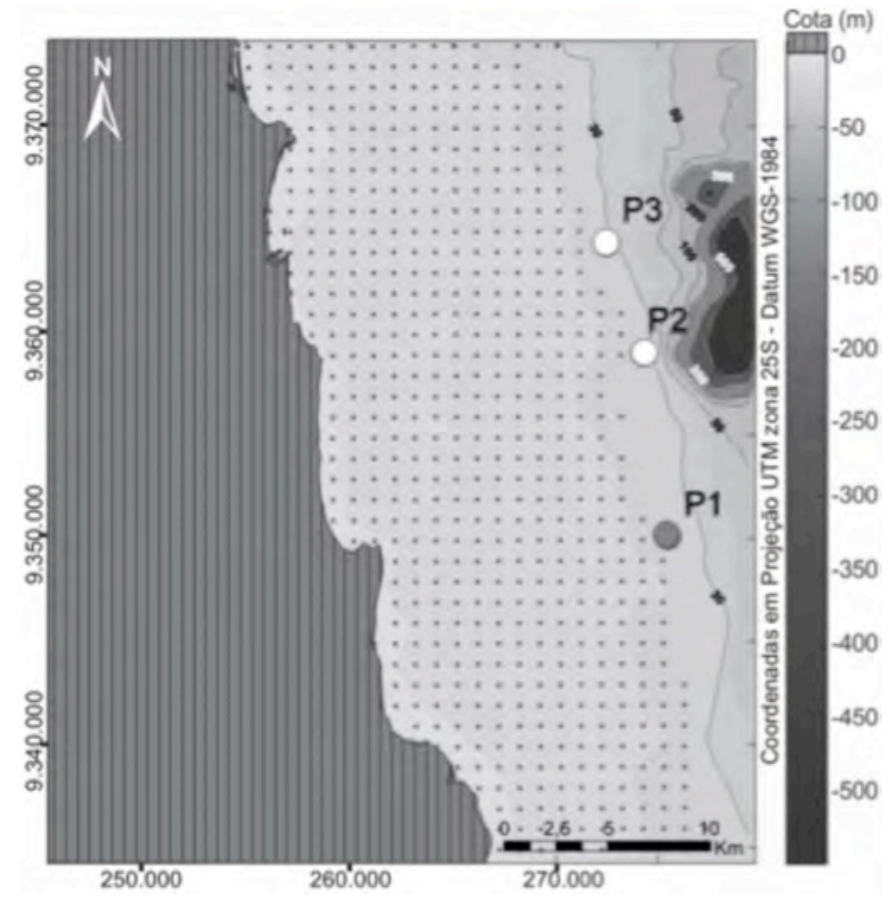

Figura 3 - Pontos DOW, com destaque para alguns dos avaliados em águas intermediárias.

Figure 3 - DOW points highlighting some of the assessment areas in intermediate water.

Portanto, neste estudo de caracterização do clima de ondas em águas intermediárias para a região da praia de Ponta Negra, diante da possível influência do cânion submerso do rio Potengi, decidiu-se por selecionar o ponto $\mathrm{P} 1$, que apresentou maiores valores de altura de onda significativa e de períodos de pico, marcando assim o pior cenário de clima marítimo para a região. $\mathrm{O}$ ponto P1 aparentemente não é influenciado pelo cânion submerso e está localizado à uma profundidade de $20 \mathrm{~m}$, em frente à praia de Ponta Negra, na latitude $5.8775^{\circ} \mathrm{S}$ e longitude $35.0301^{\circ} \mathrm{W}$ como mostra a Figura 3.

\subsection{Propagação de Ondas}

A partir dos dados obtidos no ponto DOW selecionado na posição $\mathrm{P} 1$, os espectros de ondas foram propagados utilizando o Modelo de Propagação de Ondas Espectral (OLUCA-SP), que faz parte do SMC-Brasil.

O modelo OLUCA-SP é um modelo de propagação de ondulação espectral não dispersivo que resolve a equação de declive suave (mild-slope) e agrega, 

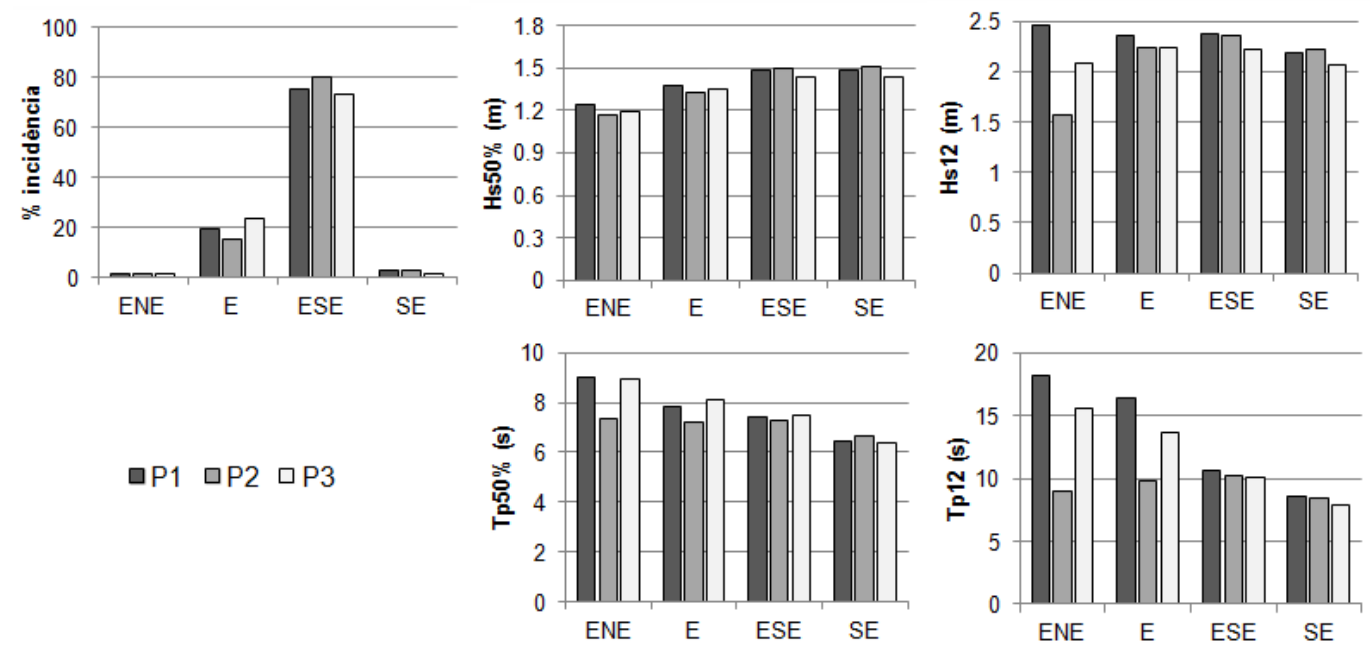

Figura 4 - Parâmetros de ondas dos pontos DOW avaliados.

Figure 4 - Wave parameters of the DOW points assessed.

também, modelos de propagação não lineares, simulação de camada limite turbulenta ou laminar, rugosidade do fundo, entre outros fatores, além de ser altamente capaz de simular todos os processos de transformação que sofrem as ondas em águas rasas na frente da zona de interesse (Camus, 2009). Para a propagação das componentes de energia, a aproximação parabólica inclui refração-difração com interação onda-corrente, através da formulação proposta por Kirby (1986), mas não a interação onda-onda provocado pela reflexão de ondas. Para a dissipação de energia devido à arrebentação das ondas foi utilizado o modelo de Battjes \& Jansen (1978) que calcula a taxa média de dissipação de energia associada a um "bore" ou degrau em movimento.

Portanto, na caracterização das ondas na praia de Ponta Negra, foram definidas propagações desde águas intermediárias, na cota batimétrica de $20 \mathrm{~m}$ no ponto $\mathrm{P} 1$, para casos relacionados às condições de tempestade (Hs12 e Tp12, valores em média superados somente 12 horas ao ano) e medianas (Hs50\% e Tp50\%) para cada uma das 4 principais direções. Tais casos foram propagados a partir da distribuição espectral de tipo Texel Marsen Arsloe (TMA, Bowns et al., 1985). O espectro TMA é aplicado em áreas próximas à costa onde as profundidades são relativamente pequenas e as ondas são afetadas pelo fundo, definido a partir de um espectro JONSWAP, e no qual se aplica a função de dispersão angular proposta por Borgman (1984). Cada espectro propagado é definido por cinco parâmetros:

Hs: Altura de onda significativa

Tp: Período de pico.

$\theta \mathrm{m}$ : Direção média.

$\gamma$ : Fator de alargamento do pico do espectro de onda.

$\sigma_{0}$ : Parâmetro de dispersão angular do espectro de onda.
Os parâmetros $\gamma$ e $\sigma_{\circ}$ de caracterização da forma do espectro bidimensional somente dependem do período de pico, onde foi definido que: se $4<\mathrm{Tp}<10, \gamma=3.3 \mathrm{e}$ $\sigma_{\mathrm{v}}=20$; se $\mathrm{Tp}>10, \gamma=8$ e $\sigma_{\mathrm{v}}=15$.

As malhas utilizadas em cada caso levaram em consideração restrições do modelo de propagação, tais como: a resolução espacial adequada à longitude de onda, que limita as dimensões das malhas; a propagação principal das ondas restrita à direção $\mathrm{X}$ e o giro das ondas circunscrito à $\pm 55^{\circ}$; as instabilidades para ondas que viajam em direção aos contornos das malhas e se encontram com batimetria que não decresce. Isso ocorre porque a propagação nos contornos laterais da malha é realizada através de uma aproximação linear (Lei de Snell) (Luca, 2011). Por esse motivo, foram necessárias malhas com contornos laterais afastados da zona de interesse. Assim, foram utilizadas três malhas, com resoluções em $\Delta \mathrm{x}$ e $\Delta \mathrm{y}$ de cerca de $20 \mathrm{~m}$ (Figura 5). A malha A foi utilizada para a propagação de ondas proveniente de ENE; a malha B para propagação de ondas de E e ESE; a malha $\mathbf{C}$ empregada na propagação das ondas proveniente de SE. Destaca-se que cada caso foi propagado em situação de maré baixa e de maré alta (maré baixa $=0 \mathrm{~m}$ e Maré Alta=2,6 m, em relação ao Nível de Redução da Carta Náutica Local), definindo diferenças de $2.6 \mathrm{~m}$ no nível do mar.

\section{Resultados e discussão}

\subsection{Ondas em Águas Intermediárias}

Considerando-se os dados gerados da base de dados do SMC-Brasil no ponto 1 (entre os anos de 1948 e 2008), verifica-se que duas direções de ondas atuam predominantemente: aquelas provenientes de leste $(\mathrm{E})$ e as de leste-sudeste (ESE), que juntas representam mais de 95\% das ondas incidentes neste ponto. Porém há a presença de ondulações de leste-nordeste (ENE) e sudeste 
(SE), como indica a Tabela 1. Na avaliação das quatro principais direções (ENE, E, ESE e SE), que somadas representam $99,9 \%$ da ondulação incidente em $\mathrm{P} 1$, se observa que para o parâmetro indicador das maiores tempestades anuais (HS12= altura de onda significava superada somente 12 horas ao ano) os valores médios foram de aproximadamente $2,4 \mathrm{~m}$ (Tabela 1). Os períodos de pico para as condições de tempestade (Tp12) variam consideravelmente entre as quatro principais direções, sendo que para ondas de tempestade provenientes de ENE, o período de pico é de $18,2 \mathrm{~s}$, enquanto que para as ondas de tempestade provenientes de SE o valor é de 8,5 s. Para as condições medianas, a altura de onda significativa (Hs50\%= altura de onda significativa mediana) variou de 1,2 a $1,5 \mathrm{~m}$ e o período de pico (Tp50\%) variou de 6,5 a 9,0 s, dependendo da direção das ondas (Tabela 1). Contudo, a direção das ondas mais frequente nesta região é de ESE, representando mais de $70 \%$ dos estados de mar em todos os pontos DOW avaliados na cota batimétrica de $20 \mathrm{~m}$ (Figura 4).

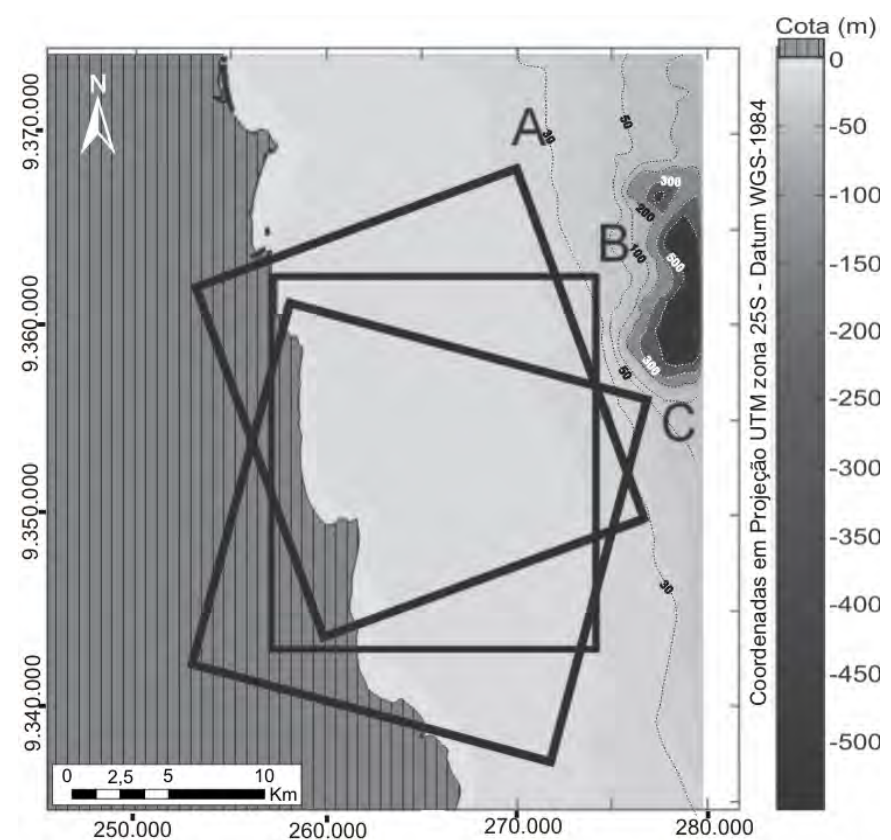

Figura 5 - Localização das malhas utilizadas nos modelos de propagação das ondas.

Figure 5 - Location of grids used in the wave propagation models.

Na Figura 6 estão representadas as rosetas direcionais das ondas, separadas por estações do ano, ou seja, verão (dezembro, janeiro e fevereiro); outono (março, abril e maio); inverno (junho, julho e agosto) e primavera (setembro, outubro e novembro). Nesta Figura é possível verificar graficamente a dominância das ondas provenientes de ESE em todas as estações do ano, porém há uma maior participação de ondas de leste no verão. As ondas com altura maior que $1,7 \mathrm{~m}$ são mais frequentes no inverno e primavera.
Tabela 1 - Caracterização do clima de ondas do ponto P1

Table 1 - Characterization of the wave climate from point P1

\begin{tabular}{|c|c|c|c|c|c|}
\hline Direção & $\begin{array}{c}\text { Prob. } \\
\text { Direção }\end{array}$ & $\mathbf{H s}_{\mathbf{5 0} \%}$ & $\mathbf{T p}_{\mathbf{5 0} \%}$ & $\mathbf{H s}_{\mathbf{1 2}}$ & $\mathbf{T p}_{\mathbf{1 2}}$ \\
\hline $\mathbf{E N E}$ & 0,0180 & 1,2465 & 9,0394 & 2,4541 & 18,1541 \\
\hline $\mathbf{E}$ & 0,1980 & 1,3769 & 7,8570 & 2,3575 & 16,3930 \\
\hline ESE & 0,7551 & 1,4871 & 7,4241 & 2,3691 & 10,6466 \\
\hline SE & 0,0281 & 1,4823 & 6,4766 & 2,1805 & 8,5077 \\
\hline
\end{tabular}

Na Figura 7 estão apresentados os resultados de avaliações dos parâmetros altura de onda significativa (Hs) e período de pico (Tp), caracterizadores do clima de onda do ponto $\mathrm{P} 1$.

A altura de onda significativa $(\mathrm{Hs})$ varia entre $0,5 \mathrm{~m}$ e $2,8 \mathrm{~m}$, sendo que $75 \%$ dos estados de mar apresentam ondas inferiores a $1,6 \mathrm{~m}$. Utilizando a Distribuição de Valores Extremos Generalizados (GEV; Fisher \& Tippett, 1928) pode-se verificar que para um período de retorno de 10 anos a altura de onda significativa do ponto $\mathrm{P} 1$ é de $2,6 \mathrm{~m}$.

O período de pico (Tp) varia entre $4 \mathrm{~s}$ e $20 \mathrm{~s}$, sendo que $75 \%$ dos estados de mar apresentam períodos de pico inferiores a $8 \mathrm{~s}$. A análise de extremos GEV nos indica que, para um período de retorno de 10 anos, o período de pico é de aproximadamente $18 \mathrm{~s}$.

As relações entre a altura de onda significativa Hs com o período de pico $\mathrm{Tp}$ e direção, verificada na distribuição conjunta Hs-Tp e Hs-Dir, indicam que as ondas mais frequentes em P1 são de alturas de onda significativa entre 1,3 e $1,7 \mathrm{~m}$, com período de pico em torno de $8 \mathrm{~s}$ e direção de ondas provenientes de $110^{\circ}$.

\subsection{Característica da Ondulação na praia de Ponta Negra}

A seguir serão apresentados os resultados da propagação dos casos, para cada uma das 4 principais direções, associados a eventos de tempestade (Hs12 e Tp12, Figura 8) e associados a condições medias de mar (Hs50\% e Tp $50 \%$, Figura 9), com os valores indicados na Tabela 1.

\section{Propagação das ondas associadas às condições de tempestade}

$\mathrm{Na}$ área de estudo se observa que para ondas provenientes de ENE (Figura 8 (a) a (d)) há pouco efeito da refração, pois o trem de ondas chega praticamente paralelo às linhas batimétricas. Na região sul da praia de Ponta Negra, devido a uma mudança na orientação das linhas batimétricas, os trens de onda provenientes de ENE sofrem o processo de refração, que tende a deixar a ondulação com direção paralela à linhas batimétricas. 


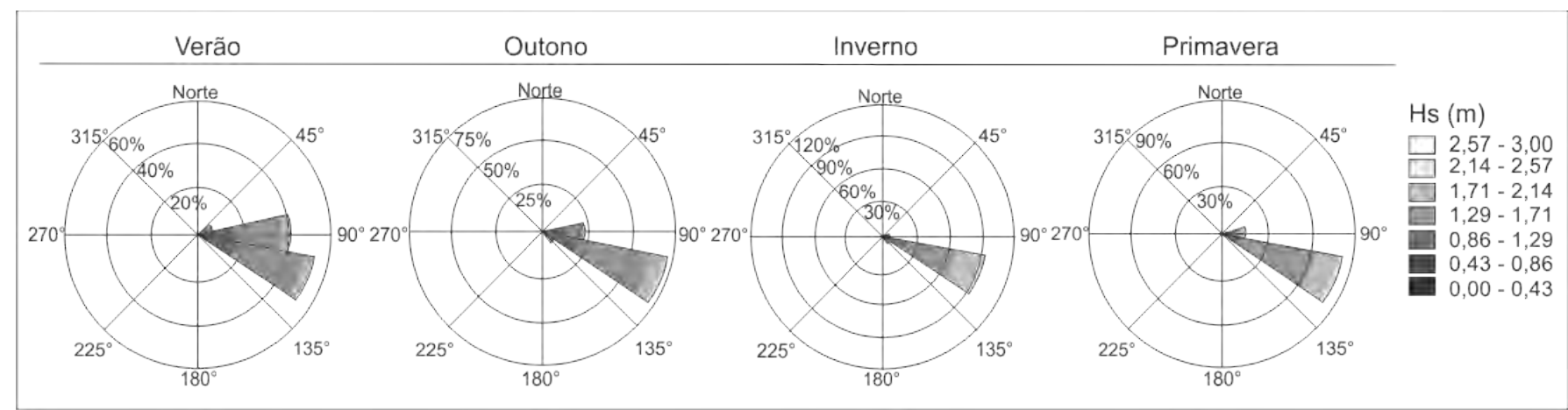

Figura 6 - Rosetas de direções de ondas do ponto P1 para cada estação do ano: verão (dezembro, janeiro e fevereiro); outono (março, abril e maio); inverno (junho, julho e agosto) e primavera (setembro, outubro e novembro).

Figure 6 - Wave directional rose at point P1 in each season: summer (December, January and February); autumn (March, April and May); winter (June, July and August); and spring (September, October and November).
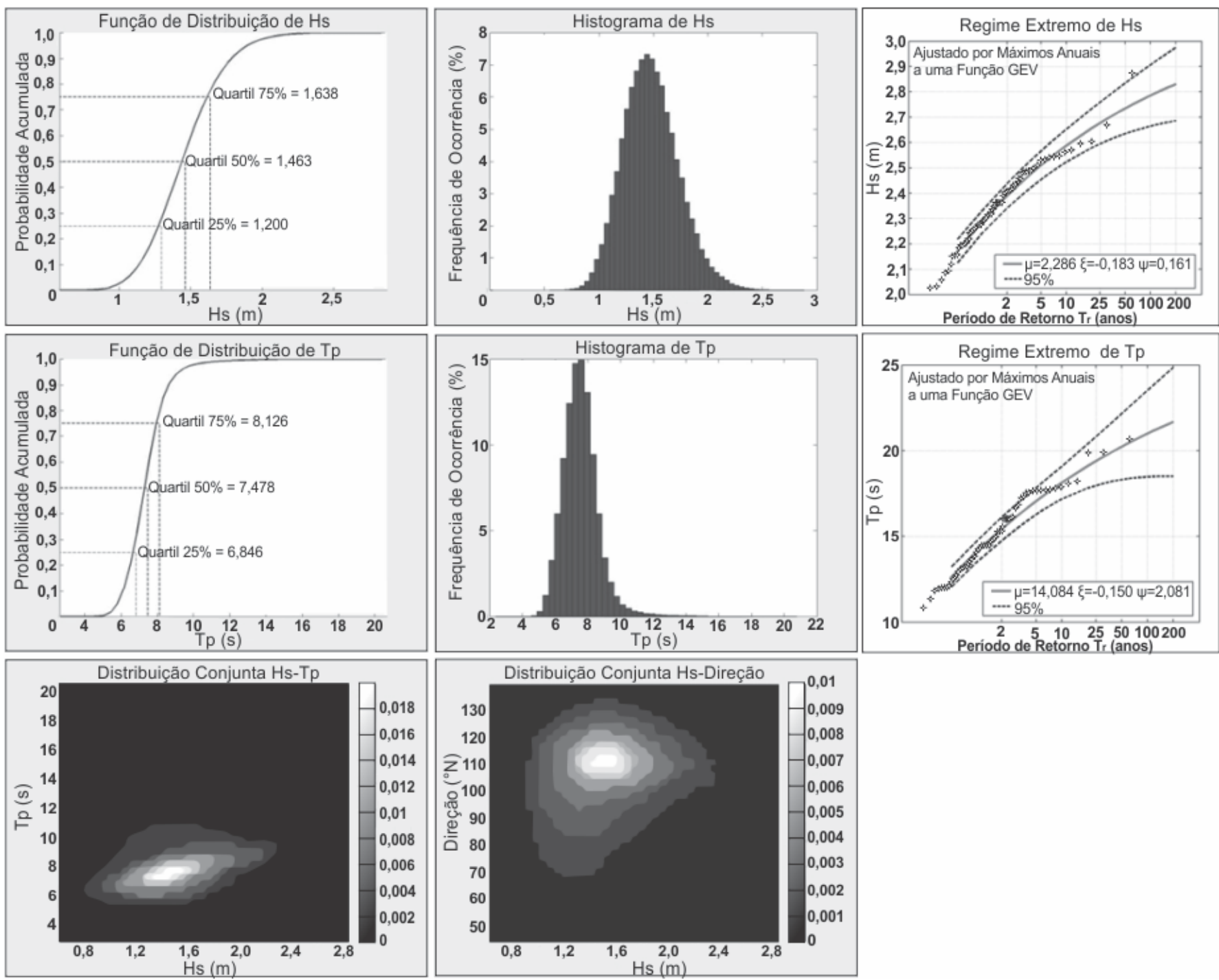

Figura 7 - Características de altura de onda significativa (Hs), de período de pico (Tp) do ponto P1.

Figure 7 - Characteristics of significant wave height (Hs) and peak period (Tp) from point Pl. 


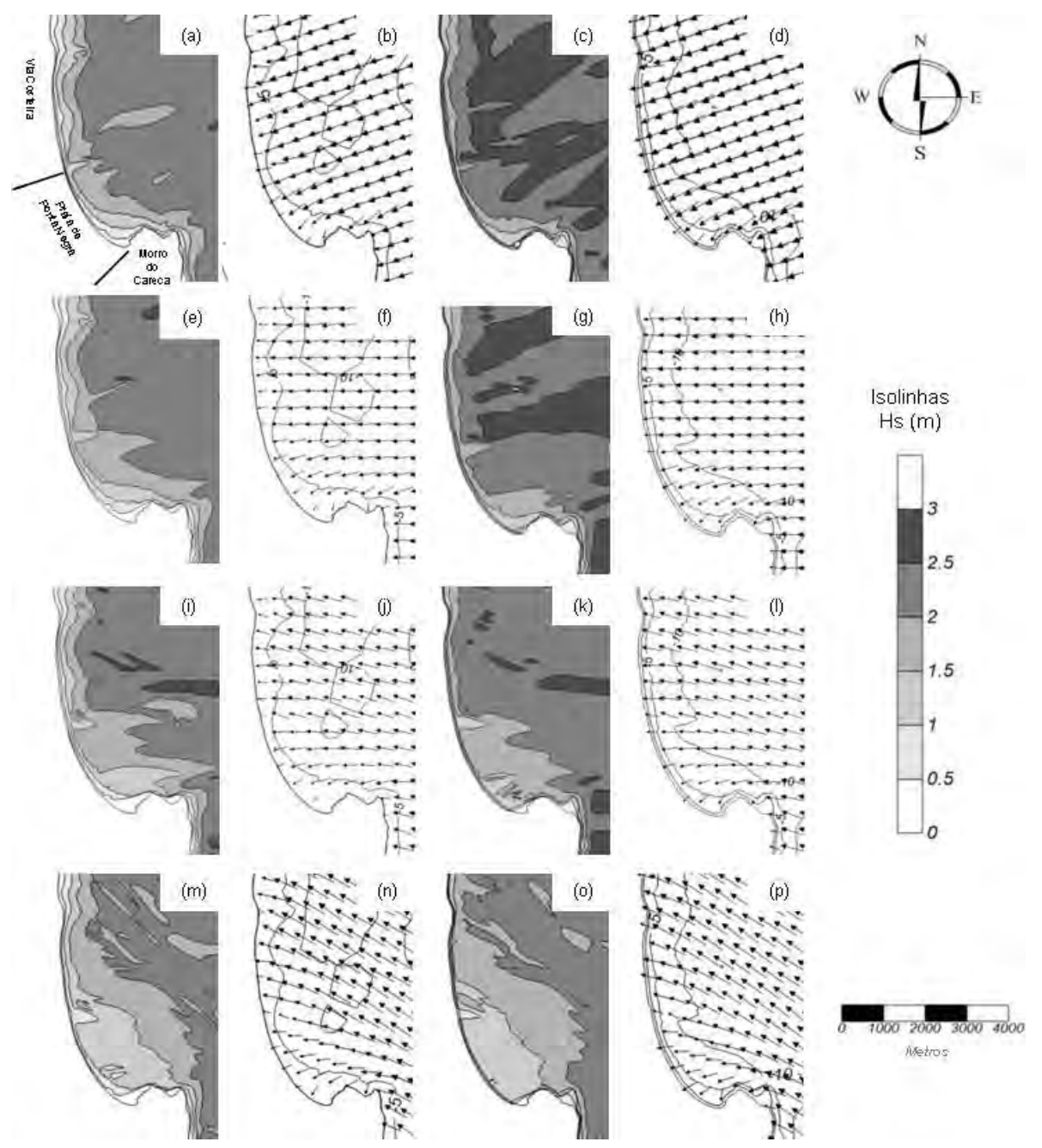

Figura 8 - Isolinhas de altura de onda e vetores de direção de ondas associados às isobatas, na região da praia de Ponta Negra resultados da propagação das ondas associadas aos eventos de tempestade: (a) e (b) ENE em baixamar; (c) e (d) ENE em preamar; (e) e (f) E em baixamar; (g) e (h) E em preamar; (i) e (j) ESE em baixamar; (k) e (l) ESE em preamar; (m) e (n) SE em baixamar; (o) e (p) SE em preamar.

Figure 8 - Wave height isolines and wave direction vectors associated with isobaths in the Ponta Negra beach region results from the wave propagation during storm conditions: (a) and (b) ENE at low tide; (c) and (d) ENE at high tide; (e) and (f) E at low tide; (g) and (h) E at high tide; (i) and (j) ESE at low tide; ( $k$ ) and (l) ESE at high tide; (m) and (n) SE at low tide; (o) and (p) SE at high tide.

Algumas vezes a refração não é completa, ou seja, o trem de ondas não gira o suficiente para ficar paralelo à linha de costa, o que faz com que a onda chegue com certa obliquidade à linha de costa e gere correntes longitudinais. Na região sul da praia de Ponta Negra, baseado numa análise visual, as ondas chegam à linha de costa com um suave ângulo para o sul. Devido aos efeitos que as ondas sofrem ao sentir o fundo marinho, que tem como consequência o empinamento das ondas e por fim sua arrebentação, à medida que se aproximam da linha de costa as ondas perdem energia e altura, comportamento este que acompanha as isóbatas. Entretanto, esta ondulação ocorreu somente em $1,8 \%$ dos casos de estado de mar entre os anos de 1948 e 2008.
Para ondulação de tempestade proveniente de E (Figura 8 (e) a (h), ocorrente em 19,8\% dos estados de mar avaliados, pode-se observar o processo de refração na praia de Ponta Negra, principalmente na região sul da praia, com diminuição na altura de onda significativa próximo à linha de costa. No gráfico de vetores é possível notar que a ondulação proveniente desta direção chega praticamente perpendicular à linha de costa.

As ondas de ESE (Figura 8 (i) a (1)), as mais frequentes da região com $75,5 \%$ dos casos de estado de mar, apresentam efeitos de refração em contato com o fundo marinho, tendendo a colocarem-se perpendiculares às isóbatas. Porém, a mudança de direção dos trens de onda devido à refração não é suficiente para deixá-los para 

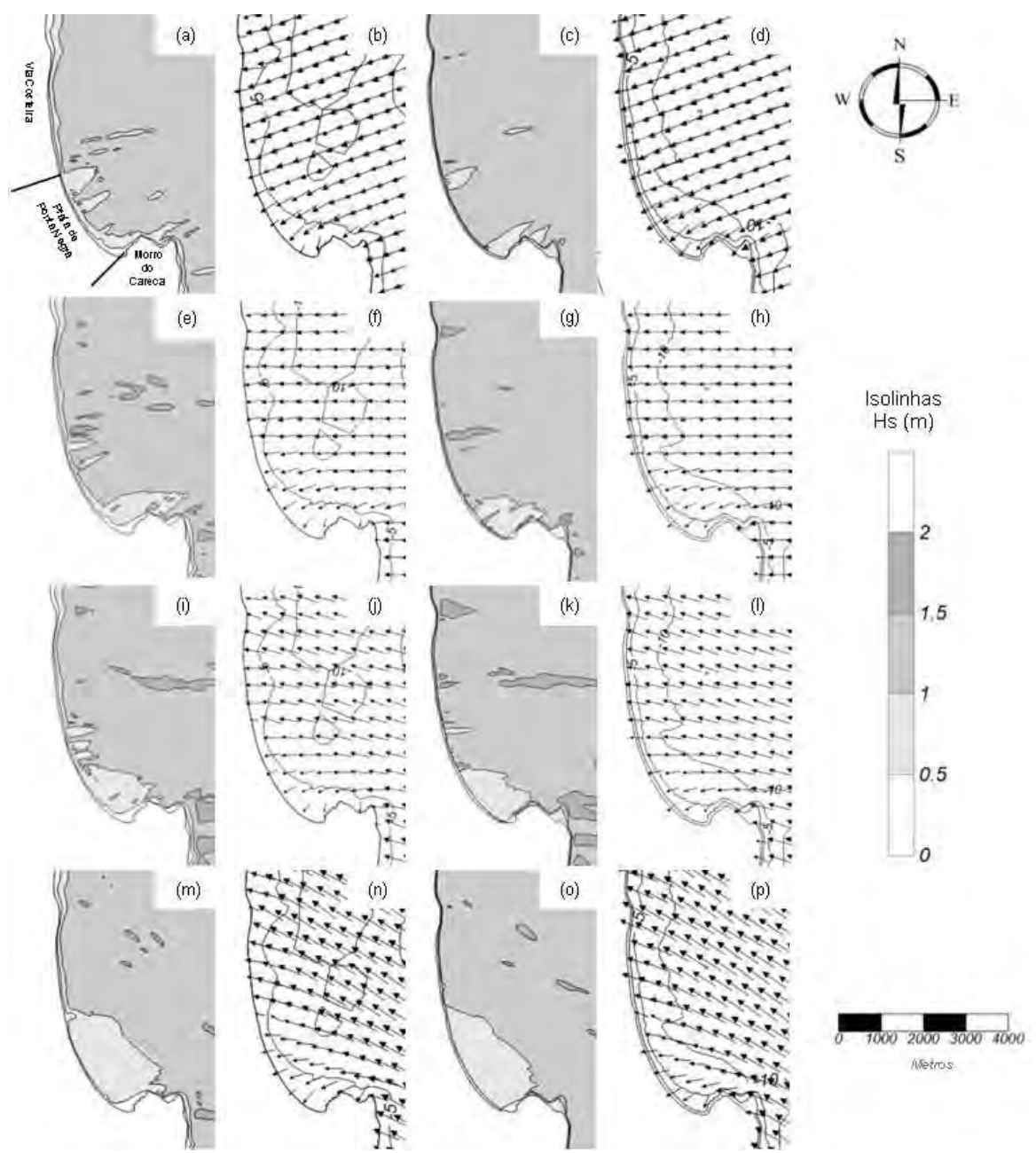

Figura 9 - Isolinhas de altura de onda e vetores de direção de ondas associados às isobatas, na região da praia de Ponta Negra, resultados da propagação das ondas associadas a condições medianas: (a) e (b) ENE em baixamar; (c) e (d) ENE em preamar; (e) e (f) E em baixamar; (g) e (h) E em preamar; (i) e (j) ESE em baixamar; (k) e (l) ESE em preamar; (m) e (n) SE em baixamar; (o) e (p) SE em preamar.

Figure 9 - Wave height isolines and wave direction vectors associated with isobaths in the Ponta Negra beach region, results from the wave propagation under normal conditions: (a) and (b) ENE at low tide; (c) and (d) ENE at high tide; (e) and (f) E at low tide; (g) and (h) E at high tide; (i) and (j) ESE at low tide; (k) and (l) ESE at high tide; ( $m$ ) and (n) SE at low tide; (o) and (p) SE at high tide.

lelos às linhas batimétricas e os gráficos de vetores evidenciam que as ondas de tempestade provenientes desta direção chegam à linha de costa com obliquidade para norte. Na zona sul da praia pode-se observar que ocorre difração.

A propagação do espectro de ondas proveniente de SE (Figura $8(\mathrm{~m})$ a (p)) mostra um importante efeito de difração decorrente do promontório onde está o Morro do Careca, chegando à praia de Ponta Negra com menor altura de onda que a ondulação que alcança a Via Costeira. Para esta ondulação pode-se observar uma importante obliquidade ao chegar à linha de costa, principalmente no norte da praia de Ponta Negra e Via Costeira, com ângulo de aproximadamente $15^{\circ}$ para norte. Assim, conclui-se que a região mais ao sul da praia de Ponta Negra está protegida de ondulações desta direção.

\section{Propagação das ondas associadas às condições medianas}

Os espectros de ondas associados às condições medianas apresentaram valores de altura de ondas significativas baixas (menores que 1,5m). Devido aos efeitos de refração, difração e arrebentação, semelhante ao observado nas ondulações associadas a condições de tempestade, estas ondulações vão perdendo energia com a diminuição da profundidade e chegam à linha de costa com valores ainda menores. Em todas as ondulações pode-se observar que a região sul da praia de Ponta Negra apresenta-se mais protegida. Na Figura 9 estão apresentados os diagramas de propagação das ondas associados a condições medianas, provenientes das direções ENE (Figura 9 (a) a (d)), E (Figura 9 (e) a (h)), ESE (Figura 9 (i) a (1)) e SE (Figura 9 (m) a (p)). 


\section{Avaliação geral da ondulação na área de estudo}

A partir dos resultados obtidos com a propagação dos casos de ondas associadas a eventos de tempestade (Figura 8) e a condições medianas (Figura 9), verificase que uma característica da praia de Ponta Negra é um gradiente de altura de onda, com menores valores na região sul, aumentando em direção à Via Costeira. Os efeitos de difração e refração foram mais importantes para as ondulações provenientes de ESE e SE, porém esta característica de gradiente de altura de onda também é observada para ondulações de ENE e E, principalmente devido aos efeitos de perda de energia das ondas em função da arrebentação das ondas, pois a batimetria na região sul da praia de Ponta Negra é tipicamente mais suave que a batimetria na região mais ao norte, sendo, portanto, mais dissipativa. $\mathrm{Na}$ região sul os valores máximos das ondas ficam em torno de $1,5 \mathrm{~m}$ para eventos de tempestade e 1,0m para condições médias. Estes valores aumentam para a região mais ao norte, atingindo ondas de até $2,5 \mathrm{~m}$ em condições de tempestade de ENE.

Comparando os resultados das propagações em condições de preamar e baixamar verifica-se que em preamar as ondulações com maior altura de onda significativa atingem a linha de costa. O que se verifica em avaliações visuais da praia é que nestas condições, devido ao processo de erosão instalado na linha de costa e à perda de sedimentos no pós-praia em diversos trechos da praia de Ponta Negra, estas ondas atualmente atingem a estrutura urbana do local, causando desestabilização da mesma.

\section{Conclusões}

A maioria das praias brasileiras sofre com problemas crônicos de erosão, que atualmente se configura como um dos principais desafios da gestão costeira no país. No planejamento e na gestão das ações voltadas à orla marítima, os fenômenos naturais e demais questões ambientais devem ser consideradas de forma intrínseca, levando a que os instrumentos gerados sejam elementos catalisadores e ordenadores de políticas de decisão para a área costeira de interesse (Moraes, 1994). Entretanto, no Brasil ainda existem grandes lacunas no entendimento do comportamento morfodinâmico das praias em escalas temporais de longo e curto prazo, resultado do baixo grau de interesse do poder público com a coleta sistemática de dados in situ sobre todos os elementos envolvidos na dinâmica da zona costeira.

A falta de dados em séries temporais contínuas, principalmente de clima de ondas, tem dificultado as análises dos aspectos morfodinâmicos das praias nas diferentes escalas de tempo, reduzindo propostas adequadas para soluções definitivas no Brasil. Através deste estudo confirmamos que o SMC-Brasil vem a contribuir para a so- lução deste problema, principalmente por ser um pacote de ferramentas e de base de dados livre, uma vez que disponibiliza uma base de dados de ondas gerada a partir da metodologia de reanálise e downscaling, que integra dados meteoceanográficos desde 1948 até 2008, minimizando desta forma a deficiência no Brasil de dados sistemáticos e de longo prazo. Entretanto, vale salientar que há a necessidade de validação local desta base de dados e dos resultados de propagações usando modelos numéricos, através da comparação com dados in situ.

Considerando-se que os cenários futuros das mudanças geomorfológicas do litoral serão totalmente regulados pela ação das forças motrizes naturais (ondas, marés, correntes e ventos) e antropogênicas, seria esperado maior comprometimento do poder público com tais questões. Uma abordagem consistente e integrada para o desenvolvimento adequado da orla marítima, baseado em modelos conceituais sistêmicos, conhecimento apropriado dos dados do meio físico e a elaboração de modelos preditivos de morfodinâmica das praias, é fundamental e desempenha o papel principal no planejamento e gestão da orla marítima. As tomadas de decisões devem basear-se em estudos específicos, realizados por técnicos conhecedores da metodologia e dos modelos usados, através da aplicação de modelagem e bases de dados, como as fornecidas pelo SMC-Brasil. Seu emprego adequado e criterioso é importante e deve ser repercutido em diversas escalas espaciais, sobretudo em setores onde a orla marítima seja considerada sob o risco de erosão e/ou inundação, com perda do uso da zona costeira, de instalações antrópicas ou ambientes de interesse ecológico, subsidiando assim as políticas e as ações de gestão costeira.

Contudo, o uso adequado de ferramentas do SMC-Brasil nos processos públicos de planejamento e gestão costeiros consiste em um grande desafio para os setores governamentais responsáveis pela implementação dessas ações, especialmente nos níveis municipal e estadual, devido à dificuldade em absorver tais informações nos processos de licenciamento ambiental, planejamento e gestão da orla marítima. $\mathrm{O}$ uso deste tipo de ferramenta deve ser incentivado, pois observa-se em outros países a aplicação exitosa de ferramentas semelhantes ao SMC-Brasil, como suporte à gestão costeira e como norteadoras de ocupações adequadas e viáveis ambiental, social e economicamente. Tal trabalho vem contribuir com este tipo de visão, apresentando importantes resultados quanto ao clima de ondas da praia de Ponta Negra.

$\mathrm{Na}$ avaliação desta base de dados para o clima de ondas, na região próxima à praia de Ponta Negra, verificou-se que há a possibilidade de que a descontinuidade no talude continental, conhecida como cânion do rio Potengi, afete as ondas associadas a eventos extremos. Sugere-se que estudos futuros sejam desenvolvidos para 
avaliar a real influência deste cânion submerso na dinâmica do clima de ondas na região de Natal.

Após a avaliação de alguns pontos DOW localizados na cota batimétrica de $20 \mathrm{~m}$, foi selecionado o ponto P1 (latitude $5.8775^{\circ} \mathrm{S}$ e longitude $35.0301^{\circ} \mathrm{W}$ ) como o mais representativo dos estados de mar na região. Assim, para águas intermediárias, as ondas são provenientes predominantemente das direções E e ESE, que juntas representam mais de $95 \%$ dos casos, com registro também de ondas de ENE e SE. Sazonalmente, a predominância de ondulações provenientes de ESE foi observada em todas as estações do ano; porém, no verão nota-se um aumento na participação de ondas originárias de $\mathrm{E}$.

Os parâmetros que caracterizam o espectro de onda do ponto $\mathrm{P} 1$ mostraram que para a região os valores de $\mathrm{Hs}$ variam entre $0,5 \mathrm{~m}$ e $2,8 \mathrm{~m}$, com $75 \%$ dos estados de mar apresentando ondas inferiores a $1,6 \mathrm{~m}$. Ondas com Hs superior a 2,6 $\mathrm{m}$ apresentam um período de retorno probabilístico de aproximadamente 10 anos. Quanto aos períodos de pico no ponto $\mathrm{P} 1$, os valores variam entre $4 \mathrm{~s}$ e $20 \mathrm{~s}$, sendo que $75 \%$ dos estados de mar apresentam Tp inferior a $8 \mathrm{~s}$. Ondas com Tp superior a $18 \mathrm{~s}$ apresentam um período de retorno probabilístico igualmente superior a 10 anos. A análise da distribuição conjunta de Hs-Tp e Hs-Dir mostrou que em P1 as ondas mais frequentes são aquelas com Hs entre 1,3 e $1,7 \mathrm{~m}, \mathrm{Tp}$ em torno de $8 \mathrm{~s}$, e provenientes da direção de $110^{\circ}$.

Na propagação desses casos espectrais verificou-se que a região sul da praia de Ponta Negra (área do Morro do Careca) é protegida da ondulação, com valores máximos registrados para $\mathrm{Hs}$ de cerca de $1,5 \mathrm{~m}$ em eventos de tempestade. Isso ocorre tanto devido aos efeitos de difração e refração, mais evidentes nas ondulações de ESE e SE, quanto também aos efeitos de perda de energia devido à presença de um fundo marinho de declividade mais suave. Deste modo, destaca-se o aumento à exposição das ondas de sul para norte na praia de Ponta Negra, em direção à praia da Via Costeira, com ondas de até $2,5 \mathrm{~m}$ alcançando a linha de costa em eventos de tempestade.

$\mathrm{Na}$ comparação entre as propagações em preamar e baixamar foi possível observar que em preamar as ondulações com maior altura de onda atingem além do que seria a face da praia e do pós praia. Tal ação pode aumentar a vulnerabilidade das estruturas urbanas instaladas neste local, fato este demonstrado por Amaro et al. (2014). Assim, este estudo destacou a grande relevância da avaliação do clima de ondas na modelagem morfodinâmica da praia de Ponta Negra, ampliando a compreensão do comportamento da praia em subsídio aos gestores da orla marítima, como garantia do uso de técnicas adequadas na avaliação de cenários preditivos de larga escala para esta praia urbana. Os resultados obtidos neste estudo representaram uma colaboração ao poder público para consolidar e ampliar as ações do Plano Nacional de Gerenciamento Costeiro - PNGC (MMA, 1997) e em consequência o Plano de Gerenciamento Costeiro do Rio Grande do Norte. Porém, medidas de dados in situ são necessárias para que estas análises sejam validadas e utilizadas de maneira adequada na gestão da praia de Ponta Negra.

Conta-se, portanto, que os resultados apresentados neste trabalho ampliem as possibilidades de estudos integrados em parceria entre os órgãos dos três níveis de governo, envolvidos na gestão integrada da orla marítima, e as instituições de ensino e pesquisa, focados nos processos erosivos e fenômenos de inundação em áreas costeiras. Mas o que se espera, primordialmente, é que tais estudos possam nortear o uso e a ocupação adequada da orla marítima do RN.

\section{Agradecimentos}

Os autores agradecem ao Ministério do Meio Ambiente (MMA), Instituto de Hidraulica Ambiental da Cantabria (IHCantabria) da Universidad de Cantabria, Ministerio de Agricultura, Alimentación y Medio Ambiente espanhol, Universidade Federal de Santa Catarina (UFSC), Universidade de São Paulo (USP), pelo patrocínio, desenvolvimento, disponibilização, incentivo e disseminação do SMC-Brasil; ao Instituto de Desenvolvimento Sustentável e Meio Ambiente (IDEMA) e Universidade Federal do Rio Grande do Norte (UFRN) pelo apoio financeiro e técnico na execução deste trabalho.

\section{References}

Almeida, L.R. (2013) - Estudio de dinámica litoral y evolución de la zona sur de la Playa de Piçarras (Santa Catarina/Brasil). 263p., Dissertação de Mestrado, Universidad de Cantabria, Santander, Espanha. Não publicado.

Amaro, V.E.; Gomes, L.R.S.; Lima, F.G.F; Scudelari, A.C.; Neves, C.F.; Busman, D.V.; Santos, A.L.S. (2014) - Multitemporal Analysis of Coastal Erosion Based on Multisource Satellite Images, Ponta Negra Beach, Natal City, Northeastern Brazil. Marine Geodesy [Published online: 19 Jun 2014]. DOI: 10.1080/01490419.2014.904257

Amaro, V.E.; Lima, F.G.F.; Santos, M.S.T. (2013) - An Evaluation of Digital Elevation Models to Short-Term Monitoring of a High Energy Barrier Island, Northeast Brazil. International Journal of Environmental, Ecological, Geological and Mining Engineering, 7(4):317-324. Disponível on-line em http://waset.org/publications/14731.

Barros, J.D.; Furtado, M.L.S.; Costa, A.M.B.; Marinho, G.S.; Silva, F.M. (2013) - Sazonalidade do vento na cidade de Natal/RN. Sociedade e Território (ISSN: 2177-8396), 25(2):78-92, Universidade Federal de Rio Grande do Norte, Natal, Brasil. Disponível on-line em http://www.periodicos.ufrn.br/sociedadee territorio/article/view/3580

Battjes, J.A.; Janssen, J.P.F.M. (1978) - Energy loss and set-up due to breaking of random waves. Coastal Engineering, 16:569-587. DOI: 10.9753/icce.v16. Disponível on-line em http://journals.tdl. org/icce/index.php/icce/article/viewFile/3294/2962

Booij, N.; Ris, R.C.; Holthuijsen, L. H. (1999) - A third-generation wave model for coastal regions. Part I: model description and validation. Journal of Geophysical Research, 104(C4):76497666. DOI: $10.1029 / 98 J C 02622$ 
Borgman, L.E. (1984) - Directional spectrum estimation for the Sxy gages. 104p., Technical Report, Coastal Engineering Research Center, Vicksburg, MS, U.S.. Não Publicado.

Bowns, E.; Gunther, H.; Rosenthal, W.; Vincent, C.L. (1985) Similarity of the wind wave spectrum in finite depth water. Journal of Geophysical Research, 90(C1):975-986. 1985. DOI: 10.1029/JC090iC01p00975

Caires, S.; Sterl, A. (2005a) - 100-year return value estimates for ocean wind speed and significant wave height from the era-40 data. Journal of Climate, 18(7):1032-1048. DOI: 10.1175/JCLI3312.1

Caires, S.; Sterl, A. (2005b) - A new non-parametric method to correct model data: application to significant wave height from the ERA-40 reanalysis. Journal of Atmospheric and Oceanic Technology, 22(4):443-459. DOI: 10.1175/JTECH1707.1

Camus, P. (2009) - Metodologías para la definición del clima maritimo en aguas profundas y someras: Aplicaciones en el corto, medio y largo plazo. 270p., Tese de doutorado, Universidad de Cantabria, Santander, Espanha. Não Publicado.

Camus, P.; Mendez F.J.; Medina, R.; Cofiño, A.S., (2011a) Analysis of clustering and selection algorithms for the study of multivariate wave climate. Coastal Engineering, 58(6):453-462. DOI: 10.1016/j.coastaleng.2011.02.003.

Camus, P.; Mendez, F.J.; Medina, R. (2011b) - A hybrid efficient method to downscale wave climate to coastal areas. Coastal Engineering 58(9):851-862. DOI: 10.1016/j.coastaleng. 2011.05 .007

Camus, P.; Mendez, F.J; Medina, R.; Tomas, A.; Izaguirre, C. (2013) - High resolution downscaled ocean waves (DOW) reanalysis in coastal areas. Coastal Engineering, 72:56-68. DOI: 10.1016/j.coastaleng.2012.09.002

CEPAL (2011) - Efectos del cambio climático en la costa de América Latina y el Caribe: Dinámicas, tendencias $y$ variabilidad climática. 263p., Organización de las Naciones Unidas (ONU),Comisión Económica para América Latina y el Caribe (CEPAL), Santiago, Chile. Disponível on-line em http://www.cepal.org/publicaciones/xml/2/45542/W.447.pdf

Cox, A.; Swail, V. (2001) - A global wave hindcast over the period 1958-1997: validation and climate assessment. Journal of Geophysical Research, 106(C2):2313-2329. DOI: 10.1029/2001JC000301

DHN (1972) - Carta náutica $n^{\circ}$ 800: da Ponta dos Três Irmãos ao Cabo Branco. $4^{\circ}$ Ed., Marinha do Brasil, Diretoria de Hidrografia e Navegação (DHN), Rio de Janeiro, RJ, Brasil.

DHN (2009) - Carta náutica $n^{\circ} 810$ - Proximidades do Porto de Natal. Marinha do Brasil, Diretoria de Hidrografia e Navegação (DHN), Rio de Janeiro, RJ, Brasil. Disponível on-line em http:// www.mar.mil.br/dhn/chm/box-cartas-raster/raster disponiveis.html

Dodet, G.; Bertin, X.; Taborda, R. (2010) - Wave climate variability in the north-east Atlantic ocean over the last six decades. Ocean Modelling, 31(3-4):120-131. DOI: 10.1016/j.ocemod.2009 .10 .010

Ferreira, A.T.S.; Amaro, V. E. ; Santos, M. S. T. (2014) - Geodésia aplicada à integração de dados topográficos e batimétricos na caracterização de superfícies de praia". Revista Brasileira de Cartografia (ISSN: 1808-0936), 66(1):167-184, Sociedade Brasileira de Cartografia, Geodésia, Fotogrametria e Sensoriamento Remoto, Rio de Janeiro, RJ, Brasil. Disponível online em http://www.lsie.unb.br/rbc/index.php/rbc/article/view/591

Fisher, R.A.; Tippett, L.H.C. (1928) - Limiting forms of the frequency distribution of the largest or smallest member of a sample. Mathematical Proceedings of the Cambridge Philosophical Society, 24(2):180-190. DOI: 10.1017/ S0305004100015681
Franke, R. (1982) - Scattered data interpolation: test of some methods. Mathematical of Computation (ISSN 0894-0347), 38(157):181-200, American Mathematical Society, Providence, RI, U.S.A. Disponível on-line em http://www.ams.org/ journals/mcom/1982-38-157/S0025-5718-1982-0637296-4/

González, M.; Medina, R.; Gonzalez-Ondina, J.; Osorio, A.; Méndez, F.J.; García, E. (2007) - An integrated coastal modeling system for analyzing beach processes and beach restoration projects, SMC. Computers \& Geosciences, 33(7):916-931. DOI: 10.1016/j.cageo.2006.12.005

Graham, N.; Diaz, H. (2001) - Evidence of intensification of north pacific winter cyclones since 1948. Bulletin of the American Meteorology Society, 82(9):1869-1893. DOI: 10.1175/15200477(2001)082<1869:EFIONP>2.3.CO;2

Guanche, Y.; Guanche, R.; Camus, P.; Mendez, F.J.; Medina, R. (2013) - A multivariate approach to estimate design loads for offshore wind turbines. Wind Energy, 16(7):1091-1106. DOI: $10.1002 /$ we. 1542

Hidroconsult (1979) - Consultoria, Estudos e Projetos. Estudo do Comportamento hidráulico do estuário e litoral adjacente à foz do Rio Potengi, Natal - Estado do Rio Grande do Norte. Relatórios Finais, v.1-2. Hidroconsult, São Paulo, SP, Brasil. Não Publicado.

Izaguirre, C.; Menéndez, M.; Camus, P.; Méndez, F.J.; Mínguez, R.; Losada, I.J. (2012) - Exploring the interannual variability of extreme wave climate in the Northeast Atlantic Ocean. Ocean Modelling, 59-60:31-40. DOI: 10.1016/j.ocemod.2012.09.007

Izaguirre, C.; Méndez, F.J.; Espejo, A.; Losada, I.J.; Reguero, B.J. (2013) - Extreme wave climate changes in Central-South America. Climatic Change, 119(2):277-290. DOI: 10.1007/s10584-013-0712-9

Kirby, J.T. (1986) - Higher-order approximations in the parabolic equation method for water waves. Journal of Geophysical Research, 91(C1):933-952.DOI: 10.1029/JC091iC01p00933

Liu, P.L.F.; Losada, I.J. (2002) - Wave propagation modeling in coastal engineering. Journal Of Hydraulic Research, 40(3):229240. DOI: $10.1080 / 00221680209499939$

Luca, C.B. (2011) - Implementação de ferramentas numéricas e bases de dados no SMC-Brasil e sua aplicação no estudo piloto da praia de Massaguaçu-Brasil. 213p., Dissertação de Mestrado, Universidade de Cantabria, Santander, Espanha. Não publicado.

Marcelino, A.M.T. (1999) - O turismo e a transformação do espaço e da paisagem litorânea potiguar. 152p., Dissertação de Mestrado, Universidade Federal do Rio Grande do Norte, Centro de Ciências Humanas, Letras e Artes. Departamento de Ciências Sociais, Natal (RN/Brasil). Não publicado.

Martínez, C.; Quezada, M.; Rubio, P. (2011) - Historical changes in the shoreline and littoral processes on a headland bay beach in central Chile. Geomorphology, 135(1-2):80-96. DOI: 10.1016/j.geomorph.2011.07.027

Medellín, G.; Medina, R.; Falqués, A.; González, M. (2008) Coastline sand waves on a low-energy beach at "El Puntal" spit, Spain. Marine Geology, 250(3-4):143-156. DOI: 10.1016/ j.margeo.2007.11.011.

MMA (1997) - Plano Nacional de Gerenciamento Costeiro II. n.p., Brasília, DF, Brasil. Disponível em http://www.mma.gov.br/ estruturas/orla/_arquivos/pngc2.pdf

MMA (2006) - Projeto orla: fundamentos para gestão integrada. $2^{\circ}$ ed., 74p., Ministério do Meio Ambiente (MMA) / Ministério do Planejamento, Orçamento e Gestão, Brasília, DF, Brasil. ISBN: 8577380297. Disponível on-line em http://www.planejamen to.gov.br/secretarias/upload/Arquivos/spu/publicacao/081021 PUB Pro jOrla fundamentos.pdf 
Moraes, A.C.R. (1994) - Meio ambiente e ciências humanas. Hucitec, 161p., São Paulo, Brasil. ISBN 85.271.0272-2

Oliveira, M. (org.). (2013) - Diálogos Brasil-Espanha: Sistema de Modelagem Costeira. 72p., Instituto Ambiental Brasil Sustentável (IABS) / Agência Espanhola de Cooperação Internacional para o Desenvolvimento (AECID) / Ministério do Planejamento (MP) / Ministério do Meio Ambiente (MMA) / Editora IABS, Brasília, DF, Brasil. ISBN: 978-8564478152

Pilar, P.; Soares, C.G.; Carretero, J.C. (2008) - 44-year wave hindcast for the north east Atlantic European coast. Coastal Engineering, $55 \quad(11): 861-871 . \quad$ DOI: $10.1016 /$ j.coastaleng.2008.02.027

Raabe, A.L.A.; Klein, A.; González, M.; Medina, R. (2010) MEPBAY \& SMC: software tools to support different operational levels of headland bay beach coastal engineering projects. Coastal Engineering, 57(2):213-226. DOI: 10.1016/j.coastaleng.2009.10.008

Reguero, B.G.; Menéndez, M.; Méndez, F.J.; Mínguez, R.; Losada; I.J. (2012) - A Global Ocean Wave (GOW) calibrated reanalysis from 1948 onwards. Coastal Engineering, 65:38-55. DOI: 10.1016/j.coastaleng.2012.03.003

Reguero, B.G.; Méndez, F.J.; Losada, I.J. (2013) - Variability of multivariate wave climate in Latin America and the Caribbean. Global and Planetary Change, 100:70-84. DOI: 10.1016/j.gloplacha.2012.09.005

Restrepo L., J. C.; Otero D., L.; López I., S.A. (2009) - Clima de oleaje en el Pacífico Sur de Colombia, delta del río Mira: comparaciones estadísticas y aplicación a procesos costeros. Revista de la Academia Colombiana de Ciencias Exactas, Físicas y Naturales (ISSN 0370-3908), 33(128):357-375, Bogotá, D.C., Colombia. Disponível on-line em http://www.accefyn.org.co/revista/Vol_33/128/357-375.pdf

Santos, M.S.T.; Amaro, V.E.; Souto, M.V.S. (2011) - Metodologia geodésica para levantamento de linha de costa e modelagem digital de elevação de praias arenosas em estudos de precisão de geomorfologia e dinâmica costeira. Revista Brasileira de Cartografia (ISSN: 1808-0936), 63(5):663-681, Sociedade Brasileira de Cartografia, Geodésia, Fotogrametria e Sensoriamento Remoto, Rio de Janeiro, RJ, Brasil. Disponível on-line em http://www.lsie.unb.br/rbc/index.php/rbc/article/view/415/402.

SMC-Brasil (2014a) - Sistema de Modelagem Costeira do Brasil. Web-page, Instituto de Hidráulica Ambiental, Universidad de Cantabria, Santander, Espanha. http://smcbrasil.ihcantabria.com.

SMC-Brasil (2014a) - Documento temático de Ondas. 155p., Instituto de Hidráulica Ambiental, Universidad de Cantabria, Santander, Espanha. Disponível on-line em http://smcbrasil.ihcantabria.com/wpcontent/uploads/2013/06/Documento_Tematico_de_Ondas.pdf/.

Sterl, A.; Komen, G.; Cotton, P. (1998) - Fifteen years of global wave hindcasts using winds from the European centre for medium-range weather forecast reanalysis: validating the reanalyzed winds and assessing the wave climate. Journal of Geophysical Research, 103(C3):5477-5492. DOI: 10.1029/97JC03431

Sterl, A.; Komen, G.; Cotton, P. (1998) - Fifteen years of global wave hindcasts using winds from the European centre for medium-range weather forecast reanalysis: validating the reanalyzed winds and assessing the wave climate. Journal of
Geophysical Research, 103(C3):5477-5492. DOI: 10.1029/97JC03431

Tavares Junior, W. (1979) - Pesquisa de modelo matemático, para simulação do espectro de energia unidimensional, de ondas de superficie geradas pelo vento (Natal, $R N, 05^{\circ} 45^{\prime} 02$ " E $035^{\circ}$ 11' 01 'W). 137p., Dissertação de Mestrado. Instituto Oceanográfico, Universidade de São Paulo, São Paulo. Não publicado.

Tintoré, J.; Medina, R.; Gómez, L.; Orfila, A.; Vizoso, G. (2009) Integrated and interdisciplinary scientific approach to coastal management. Ocean \& Coastal Management, 52(10):493-505. DOI: $10.1016 /$ j.ocecoaman.2009.08.002

Tolman, H.L. (2002) - User manual and system documentation of WAVEWATCH-III version 2.22. 133p., NOAA/NWS/NCEP Technical Note, National Oceanic and Atmospheric Administration, National Weather Service, Washington, DC, U.S.A. Disponível on-line em http://polar.ncep.noaa.gov/mmab/papers/tn222/MMAB_222.pdf

Tomás, A.; Méndez, F.J.; Losada, I.J. (2008) - A method for spatial calibration of wave hindcast data bases. Continental Shelf Research, 28(3):391-398. DOI: 10.1016/j.csr.2007.09.009

Uppala, S.M.; Kallberg, P.W.; Simmons, A.J.; Andrae U.; Bechtold, V.C.; Fiorino, M.; Gibson, J.K.; Haseler, J., Hernández, A., Kelly, G.A.; Li, X.; Onogi, K.; Saarinen, S.; Sokka, N.; Allan, R.P.; Andersson, E.; Arpe, K.; Balmaseda, M.A.; Beljaars, A.C.M.; Van De Berg, L.; Bidlot, J.; Bormann, N.; Caires, S.; Chevallier, F.; Dethof, A.; Dragosavac, M.; Fisher, M.; Fuentes, M.; Hagemann, S.; Holm, E.; Hoskins, B.J.; Isaksen, L.; Janssen, P.A.E.M.; Jenne, R.; Mcnally, A.P.; Mahfouf, J.F.; Morcrette, J.J.; Rayner, N.A.; Saunders, R.W.; Simon, P.; Sterl, A.; Trenberth, K.E.; Untch, A.; Vasiljevic, D.; Viterbo, P.; Woollen, J. (2005) - The era-40 reanalysis. Quarterly Journal of the Royal Meteorological Society, 131(612):2961-3012. DOI: 10.1256/qj.04.176

Vianello, R.L.; Alves, A.R. (1991) - Meteorologia básica e aplicações. 449p., Editora UFV, Universidade Federal de Viçosa, Viçosa, MG, Brasil. ISBN: 978-8572694322

Vital, H.; Silveira, I. M.; Amaro, V. E.; Melo, F. T. L.; Souza, F. E. S.; Chaves, M. S.; Lima, Z. M. C.; Frazao, E. P.; Tabosa, W. F.; Araújo, A. B.; Souto, M. V. S. (2006) - Rio Grande do Norte. In. D. Muehe (Org), Erosão e progradação no litoral brasileiro, pp.155-172, Ministério do Meio Ambiente (MMA), Brasília, DF, Brasil. , 476 p. ISBN 85-7738-028-9. Disponível on-line em http://www.mma.gov.br/estruturas/sqa_sigercom/_arquivos/rn_erosao.p df

Vital, H.; Silveira, M.; Amaro V.E. (2005) - Carta sedimentológica da plataforma continental brasileira - Área Guamaré a Macau (NE Brasil), utilizando integração de dados geológicos e sensoriamento remoto. Revista Brasileira de Geofisica, 23(3):233-241. DOI: 10.1590/S0102-261X2005000300003

WasaGroup (1998) - Changing waves and storms in the northeast Atlantic? Bulletin of the American Meteorology Society, 79:741-760. DOI: $10.1175 / 1520-0477(1998) 079<$ 0741:CWASIT>2.0.CO;2

Weisse, R., Von Storch, H. (2010) - Marine Climate and Climate Change - Storms, Wind Waves and Storm Surges. 219p., Springer-Praxis Books in Environmental, Heidelberg, Alemanha. ISBN: 978-3540253167. 